OPEN ACCESS

Edited by:

Daniel Roberto Perez,

University of Georgia, United States

Reviewed by:

Gary Whittaker

Cornell University, United States

Keita Matsuno,

Hokkaido University, Japan

*Correspondence:

Jens H. Kuhn

kuhnjens@mail.nih.gov

${ }^{\dagger}$ These authors have contributed equally to this work

Specialty section:

This article was submitted to

Virology,

a section of the journal

Frontiers in Microbiology

Received: 27 December 2018

Accepted: 03 April 2019

Published: 26 April 2019

Citation:

Caì Y, Yú S, Jangra RK, Postnikova EN, Wada J, Tesh RB, Whelan SPJ, Lauck M, Wiley MR,

Finch CL, Radoshitzky SR,

O'Connor DH, Palacios G,

Chandran K, Chiu CY and Kuhn JH (2019) Human, Nonhuman Primate, and Bat Cells Are Broadly Susceptible

to Tibrovirus Particle Cell Entry.

Front. Microbiol. 10:856.

doi: 10.3389/fmicb.2019.00856

\section{Human, Nonhuman Primate, and Bat Cells Are Broadly Susceptible to Tibrovirus Particle Cell Entry}

\author{
Yíngyún Caì1t, Shuíqìng Yú1t, Rohit K. Jangra ${ }^{2}$, Elena N. Postnikova ${ }^{1}$, Jiro Wada', \\ Robert B. Tesh ${ }^{3}$, Sean P. J. Whelan', Michael Lauck ${ }^{5}$, Michael R. Wiley', \\ Courtney L. Finch', Sheli R. Radoshitzky ${ }^{6}$, David H. O'Connor ${ }^{5}$, Gustavo Palacios ${ }^{6}$, \\ Kartik Chandran², Charles Y. Chiu ${ }^{7}$ and Jens H. Kuhn ${ }^{1 *}$ \\ 1 Integrated Research Facility at Fort Detrick, National Institute of Allergy and Infectious Diseases, National Institutes \\ of Health, Frederick, MD, United States, ${ }^{2}$ Department of Microbiology and Immunology, Albert Einstein College of Medicine, \\ Bronx, NY, United States, ${ }^{3}$ Department of Pathology, Center for Biodefense and Emerging Infectious Diseases, \\ The University of Texas Medical Branch, Galveston, TX, United States, ${ }^{4}$ Department of Microbiology and Immunobiology, \\ Harvard Medical School, Boston, MA, United States, ${ }^{5}$ Department of Pathology and Laboratory Medicine, University \\ of Wisconsin-Madison, Madison, WI, United States, ${ }^{6}$ United States Army Medical Research Institute of Infectious Diseases, \\ Frederick, MD, United States, ${ }^{7}$ Division of Infectious Diseases, University of California, San Francisco, San Francisco, CA, \\ United States
}

In 2012, the genome of a novel rhabdovirus, Bas-Congo virus (BASV), was discovered in the acute-phase serum of a Congolese patient with presumed viral hemorrhagic fever. In the absence of a replicating virus isolate, fulfilling Koch's postulates to determine whether BASV is indeed a human virus and/or pathogen has been impossible. However, experiments with vesiculoviral particles pseudotyped with Bas-Congo glycoprotein suggested that BASV particles can enter cells from multiple animals, including humans. In 2015, genomes of two related viruses, Ekpoma virus 1 (EKV-1) and Ekpoma virus 2 (EKV-2), were detected in human sera in Nigeria. Isolates could not be obtained. Phylogenetic analyses led to the classification of BASV, EKV-1, and EKV-2 in the same genus, Tibrovirus, together with five biting midge-borne rhabdoviruses [i.e., Beatrice Hill virus (BHV), Bivens Arm virus (BAV), Coastal Plains virus (CPV), Sweetwater Branch virus (SWBV), and Tibrogargan virus (TIBV)] not known to infect humans. Using individual recombinant vesiculoviruses expressing the glycoproteins of all eight known tibroviruses and more than 75 cell lines representing different animal species, we demonstrate that the glycoproteins of all tibroviruses can mediate vesiculovirus particle entry into human, bat, nonhuman primate, cotton rat, boa constrictor, and Asian tiger mosquito cells. Using four of five isolated authentic tibroviruses (i.e., BAV, CPV, SWBV, and TIBV), our experiments indicate that many cell types may be partially resistant to tibrovirus replication after virion cell entry. Consequently, experimental data solely obtained from experiments using tibrovirus surrogate systems (e.g., vesiculoviral pseudotypes, recombinant vesiculoviruses) cannot be used to predict whether BASV, or any other tibrovirus, infects humans.

Keywords: Bas-Congo virus, Mononegavirales, mononegavirus, Rhabdoviridae, rhabdovirus, tibrovirus, tropism, viral hemorrhagic fever 


\section{INTRODUCTION}

The viral order Mononegavirales currently includes 11 families for negative-sense single-stranded RNA viruses (Maes et al., 2019). With 18 included genera, the family Rhabdoviridae is the largest and most diverse of the mononegaviral families (Walker et al., 2018; Maes et al., 2019). Yet, viruses of most genera are undercharacterized, and their potential as human pathogens remains largely unknown. This undercharacterization holds true, for instance, for the rhabdovirus genus Tibrovirus (Bourhy et al., 2005; Gubala et al., 2011), which was suspected to harbor only viruses without any clinical or veterinary significance. However, the description of a tibrovirus associated with suspected viral hemorrhagic fever in humans in 2012 challenged this assumption (Grard et al., 2012; Chiu et al., 2013).

The prototypical tibroviruses are Tibrogargan virus (TIBV, species Tibrogargan tibrovirus), Coastal Plains virus (CPV, species Coastal Plains tibrovirus), and Bivens Arm virus (BAV, species Tibrogargan tibrovirus) (Walker et al., 2018). TIBV was first described in 1980 as a rhabdovirus infecting biting midges (Culicoides brevitaris) that were collected around Peachester, QLD, Australia, close to Mount Tibrogargan (Cybinski et al., 1980). Anti-TIBV antibodies were found in healthy cattle throughout Australia, in New Guinea, and in the United States. Antibodies were also found in healthy Australian water buffalo and a Floridian white-tailed deer, but not in Australian camels, humans, dogs, goats, horses, pigs, sheep, wallabies, and possums (Cybinski et al., 1980; Gibbs et al., 1989; Calisher et al., 1993; Gubala et al., 2011). Finally, subclinical TIBV infection was demonstrated in healthy sentinel cattle in Peachester (St George, 1985).

CPV was isolated in 1981 at Coastal Plains Research Station (today Coastal Plains Research Farm), Northern Territory, Australia, from a viremic but healthy steer. AntiCPV antibodies were detected in healthy Australian buffalo, cattle, dogs, and a horse, but not in deer, humans, pigs, or wallabies. Anti-CPV antibodies were also found in healthy cattle from Papua New Guinea (Cybinski and Gard, 1986; Gard et al., 1988).

BAV was isolated in 1982 from biting midges (Culicoides insignis) collected near water buffaloes in FL, United States, and anti-BAV antibodies were detected in healthy Floridian cattle, one horse and one white-tailed deer, but not in sheep or wildebeest (Gibbs et al., 1989). Anti-BAV antibodies were also detected in healthy Trinidadian water buffaloes (Calisher et al., 1993) and cattle from Puerto Rico and St. Croix, United States Virgin Islands (Tuekam et al., 1991).

Bivens Arm virus, CPV, and TIBV produce viral particles with rhabdovirion-characteristic bullet-like morphologies (Cybinski et al., 1980; Cybinski and Gard, 1986; Gibbs et al., 1989). However, analysis of the complete genome sequences of CPV $(13,203 \mathrm{nt})$ and TIBV $(13,298 \mathrm{nt})$ revealed a unique rhabdovirus genome organization (3'-N-P-M-U1-U2-G-U3-L-5') characterized by two novel genes of unknown function $(U 1, U 2)$ located between the matrix protein $(M)$ gene and the glycoprotein
$(G)$ gene and one gene of unknown function (U3) between the $G$ gene and RNA-dependent RNA polymerase $(L)$ gene. Each of these genes is defined as an independent transcriptional unit bounded by consensus transcription initiation and transcription termination/polyadenylation sequences. The TIBV genome differs from the CPV genome by the presence of a fourth unique open-reading frame (U4 or Gx) overlapping the G gene (Gubala et al., 2011; Walker et al., 2015).

In recent years, the genus Tibrovirus has grown steadily. Most notably, Bas-Congo virus (BASV) was identified as a tibrovirus (Walker et al., 2015). BASV was detected by nextgeneration sequencing (NGS) in an acute-phase serum sample from a human with suspected viral hemorrhagic fever in Mangala, Bas-Congo Province (today Kongo Central Province), Democratic Republic of the Congo (Grard et al., 2012). Unfortunately, a BASV isolate could not be obtained. Therefore, whether BASV indeed infects humans or causes disease remains unclear. A recent in silico analysis of the BASV genome using a novel machine learning algorithm indicates that the natural host of BASV is an artiodactyl and that BASV may be vectored by biting midges (Babayan et al., 2018). The BASV genomic sequence $(11,892 \mathrm{nt})$ remains incomplete: the sequences of all genes have been obtained except those of the $N$ and $L$ genes, which are incomplete at their extreme termini (Grard et al., 2012). Hence, a reverse genetics system to rescue replicating BASV could not yet be established and the question of BASV host tropism can therefore only be examined using indirect means.

Genomes of another two tibroviruses, Ekpoma virus 1 (EKV-1, 12,659 nt) and Ekpoma virus 2 (EKV-2, 12,674 nt), were discovered by NGS in blood samples from apparently healthy humans in Nigeria (Stremlau et al., 2015). In addition, an EKV-2-like genome detected in a human from Angola was recently deposited in GenBank (accession \#MF079256; $12,638 \mathrm{nt}$ ) but remains to be described. As in the case of BASV, cell-culture isolates for these viruses are not available, their genome sequences are incomplete at their termini (Stremlau et al., 2015), and whether any of these viruses actually infect humans, or are the cause of any human disease, remains to be confirmed.

Recently, the coding-complete BAV genome sequence (13,296 nt) was determined (Lauck et al., 2015; Walker et al., 2015), and two long-known viruses, Sweetwater Branch virus (SWBV) and Beatrice Hill virus (BHV), were identified as tibroviruses after their coding-complete genome sequences (13,141 and 13,296 nt, respectively) were determined (Walker et al., 2015; Huang et al., 2016; Wiley et al., 2017). SWBV was originally isolated in 1981 from biting midges (C. insignis) together with BAV in Florida, United States (Gibbs et al., 1989). Anti-SWBV antibodies have been detected in healthy Trinidad water buffaloes (Calisher et al., 1993). BHV was first reported in 1984 as a novel virus of biting midges (Culicoides peregrinus) that were collected at Beatrice Hill, Northern Territory, Australia (Standfast et al., 1984).

Beyond sequencing, very little research has been performed on any tibrovirus. Results of recent studies revealed structural elements of the BASV U1 protein (Buchko et al., 2017) and 
indicated that tibrovirus $U 3$ encodes a small viroporin-like transmembrane protein (Walker et al., 2015). In addition, it is suspected that BASV $G$ encodes a class III fusion glycoprotein (Steffen et al., 2013). G is the only rhabdovirus genomeencoded protein determining rhabdovirion cell entry (Altstiel and Landsberger, 1981; Wunner et al., 1984; Gaudin et al., 1993; Regan and Whittaker, 2013). Cell entry is thought to occur after G engages virus-specific cell-surface receptors or attachment factors (Bearzotti et al., 1999; Lafon, 2005; Finkelshtein et al., 2013) and subsequently mediates low-pH-induced viral and endosomal membrane fusion (Florkiewicz and Rose, 1984; Blumenthal et al., 1987; Sun et al., 2005).

Vesicular stomatitis Indiana virus (VSIV; Rhabdoviridae: Vesiculovirus: Indiana vesiculovirus) has an extremely broad, close-to-universal, cellular tropism. This broad tropism is due the fact that most cells are susceptible to VSIV G-mediated virus particle entry (cells allow virion entry) and that most cells are also permissive to VSIV replication after particle entry (cells do not restrict virus replication or virion egress) (Hastie et al., 2013). Using reverse genetics to create recombinant VSIV (rVSIV), VSIV G can easily be replaced with other mononegaviral glycoproteins, thereby possibly changing the receptor engagement of the rVSIV to that of G of the heterotypic virus, while likely maintaining the ability of the recombinant virus to replicate in most cells after particle entry (change of cell susceptibility while maintaining the same cell permissiveness).

Therefore, rVSIVs expressing heterotypic Gs can be used to perform well-controlled, initial cell susceptibility evaluations of $G$ from heterotypic viruses without including the authentic heterotypic viruses in the experiment (Garbutt et al., 2004; Tani et al., 2011; Hastie et al., 2013; Moreira et al., 2016; Robinson and Whelan, 2016; Raaben et al., 2017; Jangra et al., 2018). This approach is especially useful when the actual heterotypic viruses are only known from sequences, i.e., have not been isolated in culture (e.g., BASV, EKV-1, EKV-2). Indeed, BASV G mediates VSIV particle entry into a variety of human and nonhuman cells in a pH-dependent manner (Steffen et al., 2013). However, whether such particle cell entry (susceptibility) can be correlated to actual BASV replication (permissiveness) in the same cells remains unclear.

To further understand which cell types tibrovirus particles may enter and in which cell types authentic tibroviruses may replicate, we exposed 53 human, 11 bat, 7 nonhuman primate, 1 hispid cotton rat, 1 boa constrictor, and 1 Asian tiger mosquito cell lines to newly established infectious rVISVs encoding the eight diverse tibrovirus Gs and to four authentic tibroviruses (BAV, CPV, SWBV, and TIBV). The obtained rVSIV infections rates, which reflect tibrovirus particle cell entry (host cell susceptibility), indicate that particles of all tibroviruses, not only those of BASV, easily enter a broad range of human and nonhuman cells. We confirm $\mathrm{pH}$ dependency of BASV G-mediated entry, show that tibrovirus particle cell entry is likely dynamindependent and cholesterol-independent, and extrapolate these findings to all tibroviruses. Using the four authentic tibroviruses and cross-reacting anti-tibrovirus $\mathrm{N}$ antibodies in western blots, we demonstrate, however, that many cell lines that are susceptible to tibrovirus G-mediated particle entry are not likely to be permissive to replication of most tibroviruses after particle entry.

\section{MATERIALS AND METHODS}

\section{Viruses and Virus Infections}

Infectious rVSIV expressing enhanced green fluorescent protein (eGFP) and its native $G$ served as a control for all cell susceptibility experiments (rVSIV-VSIV G control; Figure 1A, top). Open-reading frames encoding BASV (GenBank \#JX297815.1), EKV-1 (GenBank \#KP324827), EKV-2 (GenBank \#KP324828), and SWBV (Table 1) G were synthesized by DNA2.0 (Newark, CA, United States) and cloned into the eGFP-expressing rVSIV control backbone in place of native VSIV G, as described before (Wong et al., 2010; Kleinfelter et al., 2015), yielding rVSIV-BASV G, rVSIV-EKV-1 G, rVSIV-EKV-2 G, and rVSIV-SWBV G, respectively (Figure 1A). Open-reading frames encoding BAV, BHV, CPV, and TIBV Gs were amplified by RT-PCR from infected cells (BAV, CPV, TIBV) or from infected laboratory mouse brain samples (BHV) obtained from the World Reference Center for Emerging Viruses and Arboviruses (WRCEVA) and cloned into the rVSIV control backbone in place of native VSIV G (Wong et al., 2010; Kleinfelter et al., 2015) to yield rVSIV-BAV G, rVSIV-BHV G, rVSIV-CPV G, and rVSIV-TIBV G, respectively (Figure 1A). The sequences of the G-encoding regions of all created rVSIV antigenomes were confirmed to be identical to those of the respective GenBank accession numbers by Sanger sequencing. Primers were designed to amplify rVSIV-tibrovirus G-encoding regions by RT-PCR, and these fragments were sequenced by Macrogen, Rockville, MD, United States. All rVSIVs were rescued, grown, and plaque-purified as described before (Wong et al., 2010; Kleinfelter et al., 2015).

For rVSIV expansion, adult grivet (Chlorocebus aethiops) kidney Vero cells [American Type Culture Collection (ATCC), Manassas, VA, United States; \#CCL-81] were exposed to rVSIVs $(\mathrm{MOI}=0.01)$, and cell culture supernatants were harvested once eGFP expression was observed in $\approx 60-70 \%$ of the cells. Supernatants were centrifuged to remove gross debris, used to quantify virus by plaque assay on Vero cells, aliquoted, and stored at $-80^{\circ} \mathrm{C}$ until use. Using specifically designed primers, G-encoding regions of the genomes of the expanded four authentic tibroviruses were sequenced by Macrogen to ensure that the deduced $\mathrm{G}$ amino acid sequences are identical to the respective deduced $G$ sequences from tibrovirus genomes deposited to GenBank.

Information on the four authentic tibroviruses used in this study, including their sometimes incompletely documented passaging histories, is outlined in Table 1. All four viruses were received as lyophilized powders in individual tubes. Each powder was resuspended in $1 \mathrm{ml}$ of phosphate-buffer saline (PBS). A given suspension of $100 \mu \mathrm{l}$ was added to a T75 flask containing Vero or Asian tiger mosquito (Aedes albopictus) larva C6/36 (ATCC, \#CRL-1660) cells (see below for culture conditions). Cell supernatants were harvested when cytopathic effects (CPE) affected approximately $60 \%$ of cells (designated P1; $15 \mathrm{ml} /$ flask). 
A

\begin{tabular}{|c|c|c|c|c|c|c|c|}
\hline rVSIV-VSIV G control: le & eGFP & $\mathrm{N}$ & $P$ & $\mathrm{M}$ & G & $\mathrm{L}$ & $\operatorname{tr}$ \\
\hline rVSIV-BASV G: le & eGFP & $\mathrm{N}$ & $\mathrm{P}$ & $\mathrm{M}$ & BASV-G & $\mathrm{L}$ & $\operatorname{tr}$ \\
\hline rVSIV-BAV G: le & eGFP & $\mathrm{N}$ & $\mathrm{P}$ & $M$ & BAV-G & $\mathrm{L}$ & $\operatorname{tr}$ \\
\hline rVSIV-BHV G: le & eGFP & $\mathrm{N}$ & $\mathrm{P}$ & $\mathrm{M}$ & BHV-G & $\bar{L}$ & $\operatorname{tr}$ \\
\hline rVSIV-CPV G: le & eGFP & $\mathrm{N}$ & $P$ & $\mathrm{M}$ & CPV-G & $\mathrm{L}$ & $\operatorname{tr}$ \\
\hline rVSIV-EKV-1 G: le & eGFP & $\mathrm{N}$ & $\mathrm{P}$ & $\mathrm{M}$ & EKV-1-G & $\mathrm{L}$ & $\operatorname{tr}$ \\
\hline rVSIV-EKV-2 G: le & eGFP & $\mathrm{N}$ & $\mathrm{P}$ & $\mathrm{M}$ & EKV-2-G & $\bar{L}$ & $\mathrm{tr}$ \\
\hline rVSIV-SWBV G: le & eGFP & $\mathrm{N}$ & $P$ & $\mathrm{M}$ & SWBV-G & $\mathrm{L}$ & $\operatorname{tr}$ \\
\hline rVSIV-TIBV G: le & eGFP & $\mathrm{N}$ & $\mathrm{P}$ & $M$ & TIBV-G & $\mathrm{L}$ & $\operatorname{tr}$ \\
\hline
\end{tabular}

B

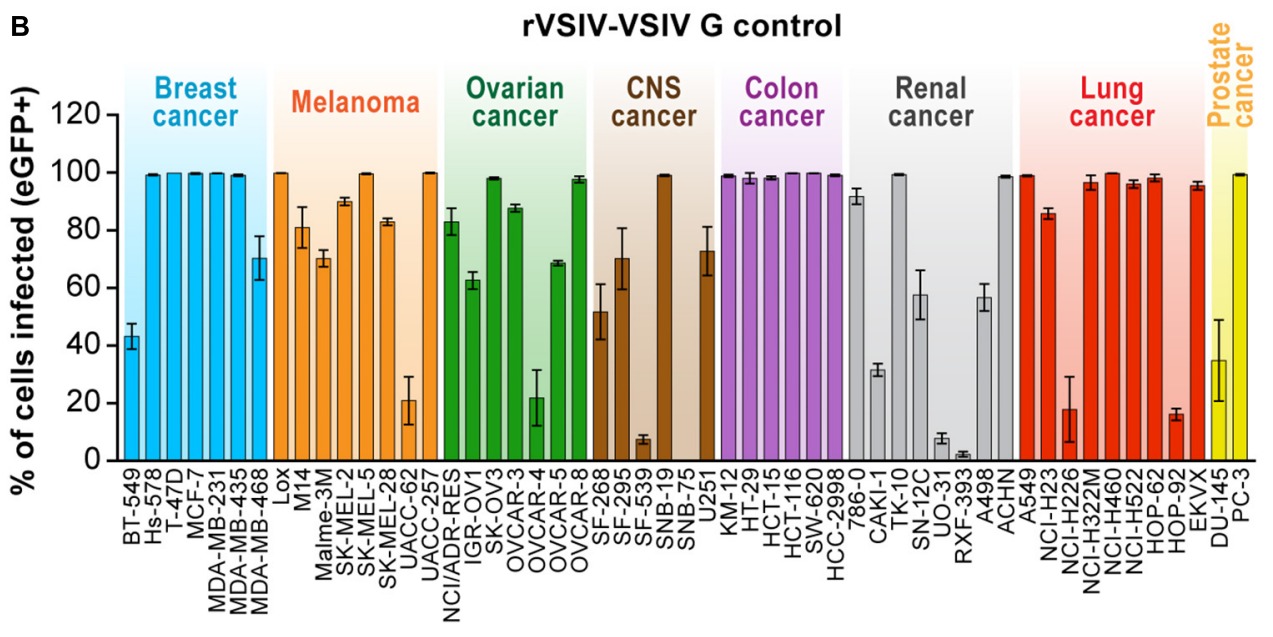

FIGURE 1 | Recombinant vesiculoviruses used in this study. (A) Genome schematic of rVSIV expressing its native G and eGFP (rVSIV-VSIV G control; top row) and rVSIVs created for this study encoding tibrovirus G instead of VSIV G (other rows). (B) Infectivity of rVSIV-VSIV G control (MOI = 3). The percentage of eGFP-expressing NCl-60 human cell panel cell lines was measured by high-content imaging at $24 \mathrm{~h}$ post-exposure ("negatives" were confirmed also at $72 \mathrm{~h}$ post-exposure, not shown). All experiments were performed in triplicate; error bars show standard deviations. BHV, Beatrice Hill virus; BASV, Bas-Congo virus; BAV, Bivens Arm virus; CNS, central nervous system, CPV; Coastal Plains virus; EKV-1, Ekpoma virus 1; EKV-2, Ekpoma virus 2; MOI, multiplicity of infection; NCl, National Cancer Institute; SWBV, Sweetwater Branch virus; TIBV, Tibrogargan virus. NCl-60 cell lines are listed by their abbreviations and grouped by organ/cancer type.

One milliliter of P1 was used to infect a T175 flask of Vero or C6/36 cells. Supernatants were harvested when CPE affected approximately $60 \%$ of cells (designated P2; $30 \mathrm{ml} /$ flask). P2 was centrifuged to remove gross debris, aliquoted, and stored at $-80^{\circ} \mathrm{C}$ until use for all tibrovirus infections performed for this study. In addition, BHV strain Commonwealth Scientific and Industrial Research Organisation (CSIRO) 25 (GenBank \#KY073493.1; Wiley et al., 2017) was kindly provided by Kim Blasdell, Australian Animal Health Laboratory (AAHL)/CSIRO, Geelong, VIC, Australia. Unfortunately, attempts to grow BHV in any culture failed, and, therefore, authentic BHV had to be omitted from this study.

\section{Cell Lines}

\section{Human}

The "NCI-60 panel," a panel of 60 highly characterized human breast, central nervous system (CNS), colon, lung, melanoma, ovarian renal cancer, and prostate cancer cell lines (Weinstein, 2006), was obtained from the US National Cancer Institute's
Developmental Therapeutics Program (NCI DTP), Frederick, MD, United States. Of these 60 cells lines, 53 adherent cell lines were used for this study. In relevant figures and tables, these cell lines are grouped by tumor classification using different colors. All NCI-60 panel cell lines were grown at $37^{\circ} \mathrm{C}$ in a humidified 5\% $\mathrm{CO}_{2}$ atmosphere in Roswell Park Memorial Institute 1640 medium (RPMI-1640, ThermoFisher Scientific, Waltham, MA, United States) supplemented with $10 \%$ heatinactivated fetal bovine serum (FBS, Sigma-Aldrich, St. Louis, MO, United States).

\section{Bat}

Eastern pipistrelle (Pipistrellus subflavus) adult lung PESU-B5L cells (Huynh et al., 2012) were kindly provide by Eric F. Donaldson, University of North Carolina at Chapel Hill, Chapel Hill, NC, United States. Egyptian rousette (Rousettus aegyptiacus) embryo Ro5T and Ro6E cells (Jordan et al., 2009) were kindly provided by Ingo Jordan, ProBioGen AG, Berlin, Germany. African straw-colored fruit bat (Eidolon helvum) adult kidney 


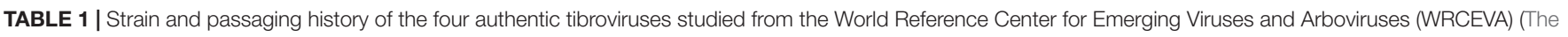
University of Texas Medical Branch (UTMB), 2018).

\begin{tabular}{|c|c|}
\hline Tibrovirus & Passaging history prior to WRCEVA deposition \\
\hline $\begin{array}{l}\text { BAV strain } \\
\text { UF-10/BT82-55 }\end{array}$ & $\begin{array}{l}\text { Isolated in } 1982 \text { from biting midges (Culicoides insignis) in Florida, United States, and then deposited to WRECA (Gibbs et al., 1989). Provided } \\
\text { by WRECA for this study after } 6 \text { intracranial (IC) passages in suckling laboratory mice, } 1 \text { IC passage in a Syrian golden hamster (Mesocricetus } \\
\text { auratus), and } 1 \text { passage in adult grivet (Chlorocebus aethiops) kidney Vero cells. Genomic sequence of this passaged virus reported in } 2015 \\
\text { [GenBank \#KM205019.1 (Walker et al., 2015) and GenBank \# KP688373.1 (Lauck et al., 2015)]. Expanded for this study in Asian tiger } \\
\text { mosquito (Aedes albopictus) C6/36 cells at } 30^{\circ} \mathrm{C} \text { until CPE affected approximately } 60 \% \text { of cells compared to non-infected control cells. }\end{array}$ \\
\hline $\begin{array}{l}\text { Coastal Plains virus } \\
\text { (CPV) strain DPP } 53\end{array}$ & $\begin{array}{l}\text { Isolated in } 1981 \text { at Coastal Plains Research Station, Northern Territory, Australia, from an apparently healthy steer (Cybinski and Gard, 1986). } \\
\text { "Passaged in cell culture a number of times" (Gubala et al., 2011) [no further information available]. Genomic sequence of this passaged virus } \\
\text { reported in } 2011 \text { [GenBank \#GQ294473.1 (Gubala et al., 2011)]. Deposited at WRECA some time prior to 1995. Provided by WRECA for this } \\
\text { study after } 4 \text { IC passages in suckling laboratory mice. Expanded for this study in C6/36 cells at } 30^{\circ} \mathrm{C} \text { until cytopathic effects (CPE) affected } \\
\text { approximately } 60 \% \text { of cells compared to non-infected control cells. }\end{array}$ \\
\hline SWBV strain UF-11 & $\begin{array}{l}\text { Isolated in } 1981 \text { from biting midges (C. insignis) in Florida, United States (Gibbs et al., 1989), and then deposited at WRECA. Provided by } \\
\text { WRECA for this study after an unknown number of undescribed passages followed by } 2 \text { passages in C6/36 cells. Genomic sequence of this } \\
\text { passaged virus reported in } 2015 \text { [GenBank \#KM204997.1 (Walker et al., 2015)]. Expanded for this study in C6/36 cells at } 30^{\circ} \mathrm{C} \text { until CPE } \\
\text { affected approximately } 60 \% \text { of cells compared to non-infected control cells. }\end{array}$ \\
\hline TIBV strain UF-10 & $\begin{array}{l}\text { Isolated in } 1976 \text { from biting midges (Culicoides brevitaris) collected around Peachester, QLD, Australia, via inoculation of midge homogenates } \\
\text { intracerebrally into suckling laboratory mice (1 passage) and then into BHK-21 cells (Cybinski et al., 1980). "Passaged in cell culture a number } \\
\text { of times" (Gubala et al., 2011) [no further information available]. Genomic sequence of this passaged virus reported in } 2011 \text { [GenBank } \\
\text { \#GQ294472.1 (Gubala et al., 2011)]. Deposited at WRECA some time prior to 1995. Provided by WRECA for this study after } 7 \text { IC passages in } \\
\text { suckling laboratory mice and } 1 \text { passage in Vero cells. Expanded for this study in Vero cells at } 37^{\circ} \mathrm{C} \text { until CPE affected approximately } 60 \% \text { of } \\
\text { cells compared to non-infected control cells. }\end{array}$ \\
\hline
\end{tabular}

EidNi/41.3 cells (Biesold et al., 2011), Büttikofer's epauletted fruit bat (Epomops buettikoferi) adult kidney EpoNi/22.1 cells, Daubenton's myotis (Myotis daubentonii) adult lung MyDauLu/47.1 cells, Egyptian rousette adult kidney RoNi7.1, hammer-headed fruit bat (Hypsignathus monstrosus) fetal lung HypLu/45.1 cells, hammer-headed fruit bat fetal kidney HypNi/1.1 cells (Kühl et al., 2011), and Egyptian rousette adult kidney RoNi/7.2 cells (Hoffmann et al., 2013) were kindly provided by Marcel A. Müller and Christian Drosten, Charité Universitätsmedizin Berlin, Germany [cells were generated with funds from the German Research Council (DR 772/10-2)]. Brazilian free-tailed bat (Tadarida brasiliensis) adult lung Tb1 $\mathrm{Lu}$ cells were obtained from ATCC (\#CCL-88). Ro5T, Ro6E, and HypNi/1.1 cells were grown in Dulbecco's modified Eagle's medium (DMEM)/F-12 (Lonza, Walkersville, MD, United States) supplemented with $10 \%$ heat-inactivated FBS. All other bat cell lines were maintained in DMEM supplemented with $10 \%$ heatinactivated FBS. All cells were incubated at $37^{\circ} \mathrm{C}$ in a humidified $5 \% \mathrm{CO}_{2}$ atmosphere.

\section{Nonhuman Primate}

Vero cells and embryonic grivet kidney MA104 cells (ATCC, \#CCL-2378) were grown at $37^{\circ} \mathrm{C}$ in a humidified $5 \% \mathrm{CO}_{2}$ atmosphere in DMEM. Primary gorilla (Gorilla gorilla) RpGor53, common chimpanzee (Pan troglodytes) S008397, and common chimpanzee RP00226 cells were obtained from Coriell Institute for Medical Research (Camden, NJ, United States) and grown under the same conditions in Eagle's Minimum Essential Medium (EMEM; Lonza) supplemented with 10\% heat-inactivated FBS.

\section{Rodent}

Hispid cotton rat (Sigmodon hispidus) lung CRL cells (ATCC, \#PTA-3920) were grown at $37^{\circ} \mathrm{C}$ in EMEM supplemented with $10 \%$ heat-inactivated FBS.

\section{Reptile}

Boa constrictor (Boa constrictor) kidney JK cells (Stenglein et al., 2012) were kindly provided by Joseph L. DeRisi, University of San Francisco, CA, United States, and grown at $30^{\circ} \mathrm{C}$ in a humidified $5 \% \mathrm{CO}_{2}$ atmosphere in EMEM with Hanks' balanced salt solution (HBSS, Lonza) supplemented with 10\% heat-inactivated FBS.

\section{Insect}

Asian tiger mosquito $\mathrm{C} 6 / 36$ cells were grown at $30^{\circ} \mathrm{C}$ in a humidified 5\% $\mathrm{CO}_{2}$ atmosphere in EMEM.

\section{Virus Infections}

Inoculation of cell lines with rVSIV-VSIV G control and rVSIVs expressing tibrovirus Gs was performed uniformly. Cell media were removed, and cells were washed once with the appropriate media without FBS. Cells were then exposed to virus particles at the indicated multiplicities of infection (MOI) and appropriate temperatures in a humidified $5 \% \mathrm{CO}_{2}$ atmosphere for $1 \mathrm{~h}$ with gentle rocking every $15 \mathrm{~min}$. Virus inocula were then removed, cells were washed once with appropriate media without FBS, and then incubated in the appropriate growth media containing $2 \%$ heat-inactivated FBS at the appropriate temperatures in a humidified $5 \% \mathrm{CO}_{2}$ atmosphere for the indicated times. The authentic tibroviruses used in this study did not cause plaques on any tested cell line, and RT-qPCR assays have not yet been established for any of them. Hence, equal volumes of virus powder suspensions were used to expose identical numbers of cells. Cells were exposed to authentic tibroviruses in a humidified $5 \% \mathrm{CO}_{2}$ atmosphere. All experiments with rVSIVs or authentic tibroviruses were performed in accredited laboratories following Institutional Biosafety Committee (IBC)-recommended biosafety level 2 procedures. 


\section{Inhibitor Studies}

Ammonium chloride, chloroquine, concanamycin A, and dynasore were obtained from Sigma-Aldrich, St. Louis, MO, United States. Dyngo-4a was kindly provided by Adam McCluskey and Volker Haucke, Freie Universität Berlin, Germany. Confluent Vero cells were exposed to the indicated concentrations of inhibitors in the appropriate medium for 30 min. rVSIV-VSIV G control or rVSIV expressing tibrovirus Gs were directly added to inhibitor-containing media. Cells were exposed for $1 \mathrm{~h}$ at $37^{\circ} \mathrm{C}(\mathrm{MOI}=0.6)$, followed by eGFP quantification $16 \mathrm{~h}$ later using an Infinite M1000 microplate reader (Tecan, Männedorf, Switzerland). The Cell Counting Kit-8 (Dojindo Molecular Technologies, Rockville, MD, United States) was used according to the manufacturer's instructions to determine the cytotoxicity of inhibitors in uninfected cells in parallel to infection assays.

\section{Detection of Tibrovirus Infection}

Infection by rVSIV-VSIV G control and rVSIVs expressing tibrovirus glycoproteins was measured by detecting eGFP expression. Cells were seeded in 96-well plates and exposed to rVSIV-VSIV G control or rVSIVs expressing tibrovirus Gs. At the indicated time points post-exposure, cells were fixed with $10 \%$ neutral-buffered formalin (NBF, ThermoFisher Scientific, Waltham, MA, United States), and their nuclei were stained with cell membrane-permeable, minor groovebinding blue fluorescent Hoechst 33342 DNA stain (Cell Signaling Technology, Danvers, MA, United States) for identification and demarcation of individual cells. High-content images were collected at $20 \times$ magnification using 4 fields of view $(\approx 1,000$ cells each) using the Operetta High-Content Imaging System (PerkinElmer, Shelton, CT, United States). Harmony 3.1 analysis software (PerkinElmer, Shelton, CT, United States) was used to quantify the percent of eGFPpositive cells. The "Analysis Sequence" was created by the Operetta operator based on the image. The basic important steps of the analysis that eliminate the possibility of falsely positive cells were: "Find Nuclei" - "Select Cell Region" (cytoplasm) - "Select Population." Positive and negative cells were determined by first creating a scatter plot of healthy cells in control wells. We considered cells as "positive" that were associated with marker intensities above those detected in the cytoplasmic regions of unexposed control cells in control wells.

Anti-CPV N and anti-TIBV N antibodies were custom-made by ThermoFisher Scientific, Waltham, MA, United States. Due to the large scale of the study, and because these antibodies were unfortunately not suitable for indirect fluorescence assays (IFAs), authentic tibrovirus infection was determined via detection of tibrovirus nucleoprotein $(\mathrm{N})$ expression by western blot. Briefly, CPV and TIBV $\mathrm{N}$ peptides were designed using Antigen Profiler software (ThermoFisher Scientific, Waltham, MA, United States). Two 19-mers were designed, produced, and injected into rabbits by the company. Rabbit sera containing antibodies were harvested and purified by the company 72 days after peptide injection. To detect authentic tibroviruses, virusexposed cells were harvested and lysed using Cell Lysis Buffer
(Cell Signaling Technology, Danvers, MA, United States) with cOmplete Protease Inhibitor Cocktail (Sigma-Aldrich, St. Louis, MO, United States) (once CPE appeared - otherwise at day 10 post-inoculation; Tables 2, 3).

Protein concentrations in each sample were measured using the bicinchoninic acid (BCA) assay (ThermoFisher Scientific, Waltham, MA, United States) following the manufacturer's instructions. Lysates were then analyzed by western blots. Protein samples $(20 \mu \mathrm{g})$ were loaded into the wells of NuPAGE 4$12 \%$ Bis-Tris Gels (ThermoFisher Scientific, Waltham, MA, United States), and gels were run with MOPS SDS Running Buffer (ThermoFisher Scientific, Waltham, MA, United States). Gels were dry-transferred using the iBlot 2 Gel Transfer Device (ThermoFisher Scientific, Waltham, MA, United States). Primary antibodies were diluted to 1:1,000; goat anti-rabbit IgG coupled to horseradish peroxidase (HRP) (Sigma-Aldrich, St. Louis, MO, United States) was diluted to 1:3,000. Protein loading was controlled by detecting cellular $\beta$-actin using anti-beta actin antibody ab8227 (Abcam, Cambridge, MA, United States). Western blotting was performed using a BlotCycler (Biocompare, South San Francisco, CA, United States) after transfer. Tibrovirus $\mathrm{N}$ bands were detected with SuperSignal West Femto Maximum Sensitivity Substrate (ThermoFisher Scientific, Waltham, MA, United States). Gel images were taken using a G:BOX gel documentation system (Syngene, Frederick, MD, United States).

\section{RESULTS}

\section{Tibrovirus Glycoproteins Mediate Virion Entry Into a Broad Range of Human and Animal Cell Types}

To improve understanding of tibrovirus cell tropism and to assess whether in vitro cell tropism of tibroviruses might be indicative of (human) host tropism, we used a wild-type rVSIV expressing its native VSIV G and eGFP (rVSIV-VSIV G control) and created rVSIVs based on this control expressing the Gs of all eight known tibroviruses (BASV, BHV, BAV, CPV, EKV-1, EKV-2, SWBV, and TIBV) in place of VSIV G (Figure 1A). We then exposed 53 wellcharacterized human adherent cancer cell lines of the "NCI-60 panel" (Weinstein, 2006) to rVSIV-VSIV G control and the eight rVSIVs encoding tibrovirus Gs $(\mathrm{MOI}=3)$ and measured virion cell entry (cell susceptibility to tibrovirus G-mediated particle entry) by quantifying the percentage of eGFP-expressing cells using high-content imaging at $24 \mathrm{~h}$ post-exposure (Figures 1B, 2). As expected, rVSIV-VSIV G control infected almost all cell lines, with the notable exceptions of one CNS cancer cell line (SNB-75) and one renal cancer cell line (RXF-393). Hence, these two cell lines are not susceptible, not permissive, or not susceptible and not permissive to VSIV infection. rVSIV-VSIV G control infection occurred in $100 \%$ of cells in 25 of the 53 tested cell lines, and infection efficiency was approximately $\leq 50 \%$ in 8 of them (Figure 1B).

Due to the overall known broad cell tropism of VSIV (Hastie et al., 2013) and the assumption that VSIV uses a different cell-surface receptor or attachment factor than tibroviruses, we 
TABLE 2 | Detection of authentic tibroviruses in human cell lines.

\begin{tabular}{|c|c|c|c|c|c|c|c|c|c|}
\hline \multirow[t]{2}{*}{ Tissue origin } & \multirow[t]{2}{*}{$\mathrm{NCl}-60$ panel cell line } & \multicolumn{2}{|c|}{ TIBV } & \multicolumn{2}{|c|}{ BAV } & \multicolumn{2}{|c|}{ SWBV } & \multicolumn{2}{|c|}{ CPV } \\
\hline & & CPE & WB & CPE & WB & CPE & WB & CPE & WB \\
\hline \multirow[t]{7}{*}{ Breast cancer } & BT-549 & Yes & + & No & - & No & - & No & - \\
\hline & Hs-578T & No & + & No & - & No & - & No & - \\
\hline & $\mathrm{T}-47 \mathrm{D}$ & Yes & + & No & - & No & - & No & - \\
\hline & MCF-7 & Yes & + & No & - & No & - & No & - \\
\hline & MDA-MB-231 & Yes & + & No & - & No & - & No & - \\
\hline & MDA-MB-435 & Yes & + & No & - & No & - & No & - \\
\hline & MDA-MB-468 & No & $(+)$ & No & - & No & - & No & - \\
\hline \multirow[t]{8}{*}{ Melanoma } & Lox & Yes & + & No & - & No & - & No & - \\
\hline & $\mathrm{M} 14$ & Yes & + & Yes & - & No & - & No & - \\
\hline & Malme-3M & Yes & + & No & - & No & - & No & - \\
\hline & SK-MEL-2 & Yes & + & No & - & No & - & No & - \\
\hline & SK-MEL-5 & Yes & + & No & - & No & - & Yes & + \\
\hline & SK-MEL-28 & Yes & + & No & - & No & - & No & - \\
\hline & UACC-62 & Yes & + & No & - & No & - & No & - \\
\hline & UACC-257 & Yes & + & No & - & No & - & No & - \\
\hline \multirow[t]{7}{*}{ Ovarian cancer } & $\mathrm{NCl} / \mathrm{ADR}$-RES & Yes & + & No & - & No & - & No & - \\
\hline & IGR-OV1 & Yes & + & No & - & No & - & No & - \\
\hline & SK-OV3 & Yes & + & No & - & No & - & No & - \\
\hline & OVCAR-3 & Yes & + & No & - & No & - & No & - \\
\hline & OVCAR-4 & Yes & + & No & - & No & - & No & - \\
\hline & OVCAR-5 & Yes & + & No & - & No & - & No & - \\
\hline & OVCAR-8 & Yes & + & No & - & No & - & No & - \\
\hline \multirow[t]{6}{*}{ CNS cancer } & SF-268 & Yes & + & No & - & No & - & No & - \\
\hline & SF-295 & Yes & + & No & - & No & - & No & - \\
\hline & SF-539 & Yes & + & Yes & - & No & - & No & - \\
\hline & SNB-19 & Yes & + & No & - & No & - & No & - \\
\hline & SNB-75 & Yes & + & No & - & No & - & No & - \\
\hline & U251 & Yes & + & No & - & No & - & No & - \\
\hline \multirow[t]{6}{*}{ Colon cancer } & $\mathrm{KM}-12$ & Yes & + & No & - & No & - & No & - \\
\hline & HT-29 & Yes & - & No & - & No & - & No & - \\
\hline & НCT-15 & Yes & + & No & - & No & - & No & - \\
\hline & НСТ-116 & Yes & + & No & - & No & - & No & - \\
\hline & SW-620 & Yes & + & No & - & No & - & No & + \\
\hline & HCC-2998 & Yes & + & Yes & - & No & - & No & - \\
\hline \multirow[t]{8}{*}{ Renal cancer } & $786-0$ & Yes & + & No & - & No & - & No & - \\
\hline & CAKI-1 & Yes & + & No & - & No & - & No & - \\
\hline & TK-10 & Yes & + & No & - & No & - & No & - \\
\hline & SN-12C & Yes & + & No & - & No & - & No & - \\
\hline & UO-31 & Yes & + & No & - & No & - & No & - \\
\hline & RXF-393 & Yes & + & No & - & No & - & No & - \\
\hline & A498 & Yes & + & Yes & - & No & - & No & - \\
\hline & $\mathrm{ACHN}$ & Yes & + & No & + & No & - & No & - \\
\hline \multirow[t]{9}{*}{ Lung cancer } & A549 & Yes & + & No & + & No & - & No & - \\
\hline & $\mathrm{NCl}-\mathrm{H} 23$ & Yes & + & No & + & No & - & No & + \\
\hline & $\mathrm{NCl}-\mathrm{H} 226$ & Yes & + & No & - & No & - & No & - \\
\hline & $\mathrm{NCl}-\mathrm{H} 322 \mathrm{M}$ & Yes & + & No & - & No & - & No & - \\
\hline & $\mathrm{NCl}-\mathrm{H} 460$ & Yes & + & No & + & No & - & No & - \\
\hline & $\mathrm{NCl}-\mathrm{H} 522$ & Yes & + & Yes & + & No & - & No & + \\
\hline & HOP-62 & Yes & + & Yes & - & No & - & No & - \\
\hline & HOP-92 & Yes & + & No & - & No & - & No & - \\
\hline & EKVX & Yes & $(+)$ & No & - & No & - & No & - \\
\hline \multirow[t]{2}{*}{ Prostate cancer } & DU-145 & Yes & + & No & - & No & - & No & - \\
\hline & PC-3 & Yes & + & No & - & No & - & No & - \\
\hline
\end{tabular}

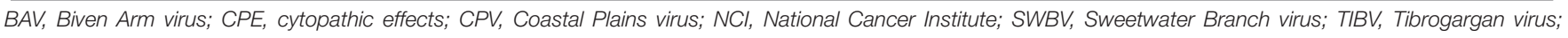
WB, western blot. 
TABLE 3 | Detection of authentic tibroviruses in nonhuman cell lines.

\begin{tabular}{|c|c|c|c|c|c|c|c|c|c|}
\hline \multirow{2}{*}{$\begin{array}{l}\text { Tissue } \\
\text { origin }\end{array}$} & \multirow[t]{2}{*}{ Cell line } & \multicolumn{2}{|c|}{ TIBV } & \multicolumn{2}{|c|}{ BAV } & \multicolumn{2}{|c|}{ SWBV } & \multicolumn{2}{|c|}{ CPV } \\
\hline & & CPE & WB & CPE & WB & CPE & WB & CPE & WB \\
\hline \multirow[t]{11}{*}{ Bat } & B5L & No & - & No & - & No & - & No & - \\
\hline & Ro5T & Yes & + & No & - & No & - & No & - \\
\hline & Ro6E & No & - & No & - & Yes & - & No & - \\
\hline & Tb1 Lu & No & - & No & - & No & - & No & - \\
\hline & EidNi/41.3 & Yes & + & No & - & No & - & No & - \\
\hline & EpoNi/22.1 & No & - & No & - & No & - & No & - \\
\hline & RoNi/7.1 & No & - & No & - & No & - & No & - \\
\hline & $\mathrm{RoNi} / 7.2$ & No & - & No & - & No & - & No & - \\
\hline & HypNi/1.1 & Yes & + & No & - & No & - & No & - \\
\hline & HypLu/45.1 & Yes & + & No & - & No & - & No & - \\
\hline & MyDauLu/47.1 & Yes & + & No & - & No & - & No & - \\
\hline \multirow{4}{*}{$\begin{array}{l}\text { Nonhuman } \\
\text { primate }\end{array}$} & MA104 & No & $(+)$ & No & - & No & - & No & - \\
\hline & PRGor53 & No & + & No & - & No & - & No & - \\
\hline & S008397 & No & + & No & - & No & - & No & - \\
\hline & PR00226 & No & $(+)$ & No & - & No & - & No & - \\
\hline Rodent & $\mathrm{CRL}$ & No & - & No & - & No & - & No & - \\
\hline Snake & JK & Yes & + & No & - & No & - & No & - \\
\hline
\end{tabular}

BAV, Biven Arm virus; CPE, cytopathic effects; CPV, Coastal Plains virus; SWBV, Sweetwater Branch virus; TIBV, Tibrogargan virus; WB, western blot.

expected rVSIVs expressing tibrovirus Gs in place of VSIV G to enter fewer cell lines with less efficiency than rVSIV-VSIV G control. Assuming that within-cell VSIV restriction factors do not target $\mathrm{G}$, we further surmised that rVSIV-VSIV G control and rVSIVs expressing a tibrovirus $G$ would replicate at similar efficiencies in cells that permit entry of both viruses, i.e., that these cells would be equally permissive. Interestingly, rVSIV-BAV [3 negative cell lines, 19 cell lines with $\approx 100 \%$ infection efficiency ("negative": all percentages $<1 \%$; “ $\approx 100 \%$ ": reaching $100 \%$ on average/within the standard deviation)], rVSIV-BASV (4 negative cell lines, 11 cell lines with $\approx 100 \%$ infection efficiency), rVSIV-SWBV (6 negative cell lines, 21 cell lines with $\approx 100 \%$ infection efficiency), and rVSIV-TIBV (5 negative cell lines, 23 cell lines with $\approx 100 \%$ infection efficiency) fulfilled the first assumption, but not necessarily the second (Figure 2).

Even more surprisingly, rVSIVs expressing Gs of the remaining tibroviruses equaled or outperformed rVSIV-VSIV $G$ control in number of cell types infected and/or infection efficiency. Most notably, rVSIV-EKV-1 and rVSIV-EKV-2 entered and replicated in all tested cell lines. Only two cell lines were infected with approximately $\leq 50 \%$ efficiency, and 44 cell lines (rVSIV-EKV-1) or 40 cell lines (rVSIV-EKV-2) were infected with $\approx 100 \%$ efficiency (Figure 2 ). Importantly, cell lines resistant to rVSIV-VSIV G control infection (i.e., CNS SNB-75, RXF-393) were not necessarily resistant to infection with rVSIVs expressing certain tibrovirus Gs. For instance, the SNB-75 cell line was efficiently infected with rVSIV-BHV $(\approx 80 \%)$ and rVSIV-CPV $(\approx 45 \%)$. The cell line was inefficiently infected with rVSIV-BAV, rVSIV-EKV-1, rVSIV-EKV-2, and rVSIV-TIBV and not at all infected with rVSIV-BASV and rVSIV-SWBV. Likewise, the renal cancer RXF-393 cell line was efficiently infected with rVSIV-BAV, rVSIV-BHV, rVSIV-EKV1, rVSIV-EKV-2, and rVSIV-TIBV, inefficiently infected with rVSIV-BASV and rVSIV-CPV, and resistant to rVSIV-SWBV. Together, these results indicate that all tibroviruses may be able to broadly enter human cell types and that individual tibrovirus Gs bestow different cell tropism patterns. Furthermore, these data indicate that resistance of SNB-75 and RXF-393 cells to rVSIVVSIV G control occurs at the VSIV particle entry step and is not due to replication restriction as rVSIVs encoding some non-VSIV Gs were able to replicate in these cells.

To determine whether tibrovirus Gs also mediate virion entry into nonhuman cell lines, we exposed 11 bat, 5 nonhuman primate, 1 hispid cotton rat, 1 boa constrictor, and 1 Asian tiger mosquito cell lines to rVSIV-VSIV G control and the 8 rVSIVs expressing tibrovirus Gs (Figure 3). Two bat cell lines, PESU-B5L and MyDauLu/47.1, were almost uniformly resistant to infection (virus particle entry and/or subsequent replication), and only a low level of infection by rVSIV-SWBV was detected in PESU-B5L cells. Tb1 Lu cells were resistant to rVSIV-BASV, rVSIV-EKV-1, and rVSIV-VSIV G control but were susceptible to all other viruses. $\mathrm{RoNi} / 7.1$ cells were resistant to rVSIV-BASV, rVSIV-BHV, rVSIV-CPV, rVSIV-EKV-1, and rVSIV-TIBV. All other bat cell lines were variably susceptible and permissive to all rVSIVs (Figure 3A). All nine rVSIVs infected hispid cotton rat CRL, boa constrictor JK, and nonhuman primate MA104 and Vero cells with high efficiency. However, gorilla (RPGor53) cells could not be infected by rVSIV-VSIV G control or rVSIV-SWBV, and common chimpanzee (S008397 and RP00226) cells were highly susceptible to rVSIV-CPV but much less susceptible or resistant to the other rVSIVs expressing tibrovirus Gs (Figure 3A). 


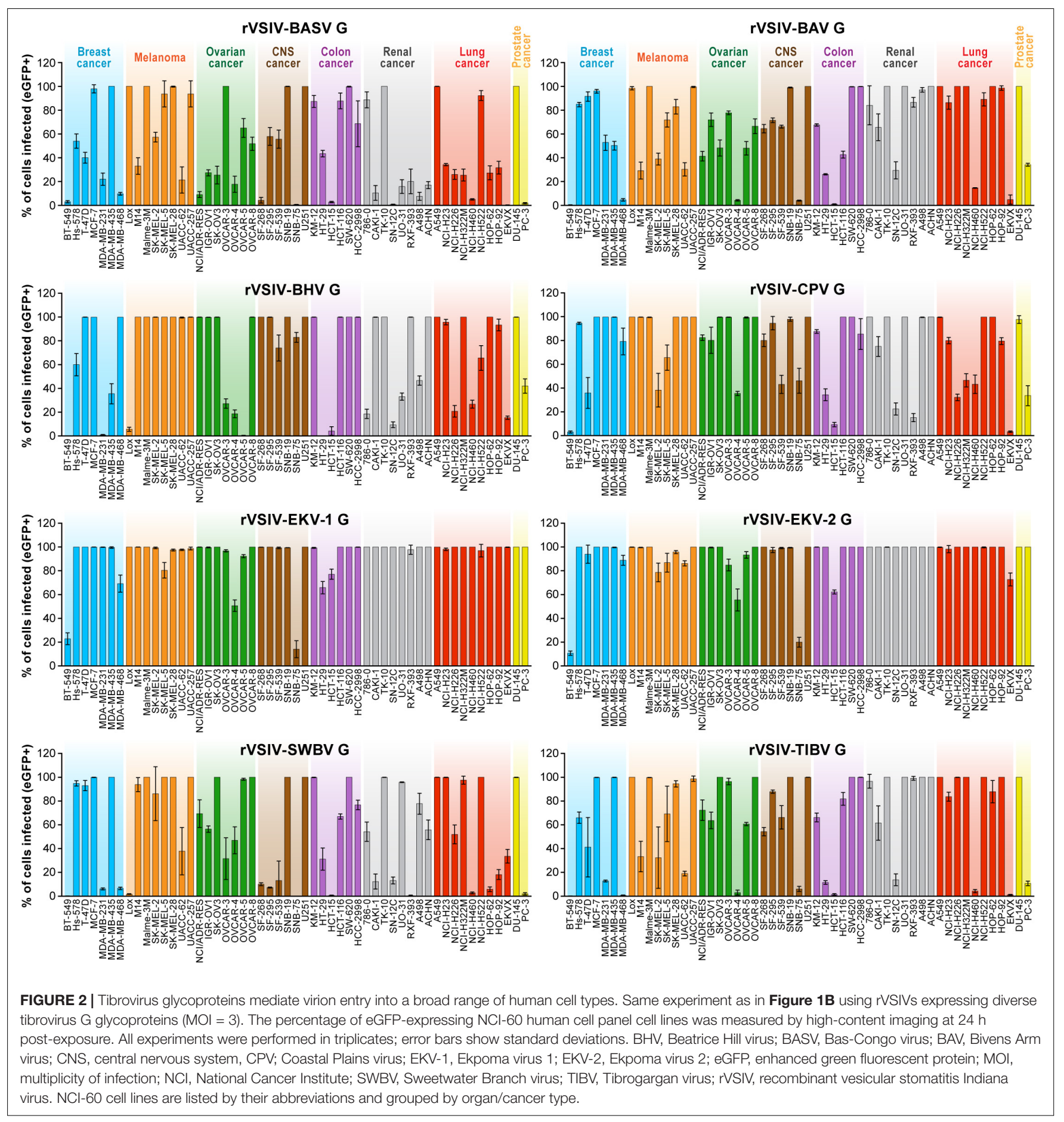

Finally, all viruses infected Asian tiger mosquito (C6/36) cells, but infection only became apparent at $\approx 72 \mathrm{~h}$ post-exposure. Interestingly, rVSIV-VSIV G control infected these cells least efficiently compared to all other viruses (Figure 3B). Together, these results indicate that tibroviruses may be able to broadly enter non-human cell lines, but some cell lines (e.g., PESU-B5L and MyDauLu/47.1) may not be permissive to VSIV replication after particle entry.
The experiments above were performed with high amounts of rVSIVs $(\mathrm{MOI}=3)$ as our primary objective was to determine whether different cells types are absolutely susceptible or resistant to tibrovirus G-mediated particle entry. To determine relative differences, we repeated the experiments with a MOI $=0.3$ (Supplementary Figures S1, S2). As expected, percentages of rVSIV-infected cells were generally decreased in the lower MOI experiment, but numerous cell lines were 

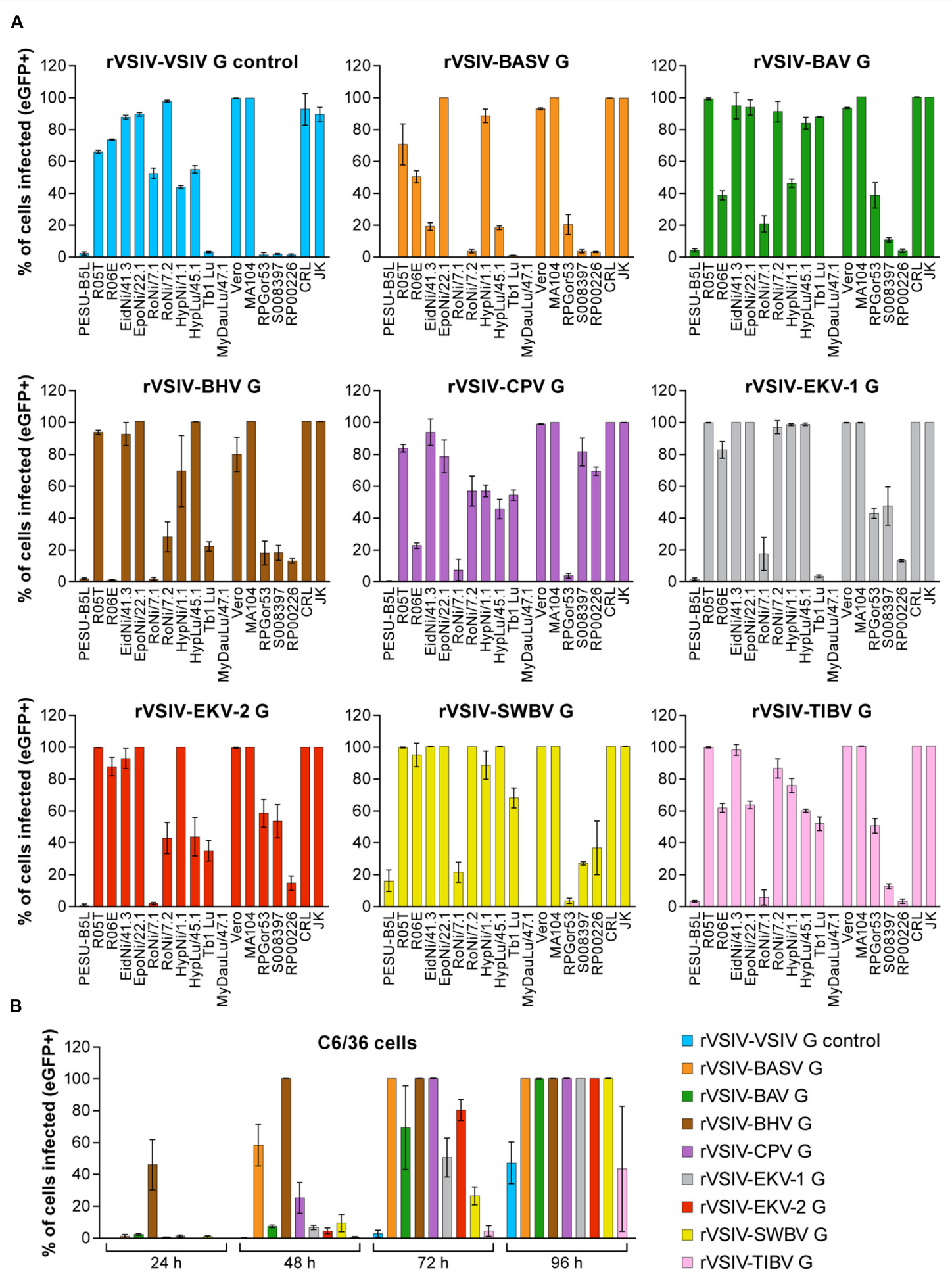

FIGURE 3 | Tibrovirus glycoproteins mediate virion entry into a broad range of animal cell types. Same experiment as in Figures $\mathbf{1 B}$, $\mathbf{2}$ using different cell types exposed to rVSIV-VSIV G control and rVSIVs expressing diverse tibrovirus glycoproteins (G) (MOI = 3). (A) Bat (PESU-B5L, Ro5T, Ro6E, EidNi/41.3, EpoNi/22.1, RoNi/7.1, RoNi/7.2, HypNi/1.1, HypLu/45.1, Tb1 Lu, MyDauLu/47.1), nonhuman primate (Vero, MA104, RPGor53, S008397, RP00226), hispid cotton rat CRL, and boa constrictor $\mathrm{JK}$ cell lines. (B) Asian tiger mosquito C6/36 cells. The percentage of eGFP-expressing cell lines was measured by high-content imaging at $24 \mathrm{~h}$ post-exposure (bat, nonhuman primate, hispid cotton rat, and boa constrictor cell lines) or at 24, 48, 72, and 96 h post-exposure (Asian tiger mosquito cells). All experiments were performed in triplicate; error bars show standard deviations. BHV, Beatrice Hill virus; BASV, Bas-Congo virus; BAV, Bivens Arm virus; CPV, Coastal Plains virus; eGFP, enhanced green fluorescent protein; EKV-1, Ekpoma virus 1; EKV-2, Ekpoma virus 2; MOI, multiplicity of infection; SWBV, Sweetwater Branch virus; TIBV, Tibrogargan virus; rVSIV, recombinant vesicular stomatitis Indiana virus. 
still infected at the $100 \%$ level. Most strikingly, rVSIV-EKV-1 and rVSIV-EKV-2 infection rates among human cell lines barely diminished, suggesting that EKV-1 and EKV-2 are more efficient in entering human cell lines compared to all other tibroviruses.

\section{Tibrovirus Particle Host Cell Entry Is Dependent on Low pH and Dynamin but Is Independent of Cholesterol}

Rhabdovirion cell entry is thought to generally occur by a $\mathrm{pH}$ dependent mechanism (Florkiewicz and Rose, 1984; Blumenthal et al., 1987; Sun et al., 2005). Previously, rVSIV particles devoid of VSIV G and pseudotyped with BASV G were also confirmed to enter target cells in a pH-dependent manner (Steffen et al., 2013). To evaluate whether all tibrovirus Gs function analogously, we chose a common cell line universally susceptible to tibrovirus G-mediated particle entry (Vero cells, Figure 3A). These cells were pretreated with increasing concentrations of endosomal $\mathrm{pH}$ modulators (lysosomotropic weak bases $\mathrm{NH}_{4} \mathrm{Cl}$, chloroquine or vacuolar type $\mathrm{H}^{+}$-ATPase inhibitor concanamycin A) for $30 \mathrm{~min}$ followed by exposure to rVSIV-VSIV G control and all 8 rVSIVs expressing tibrovirus Gs at MOI $=0.6$ in the presence of these modulators for $1 \mathrm{~h}$. At $16 \mathrm{~h}$, we quantified eGFP expression. As previously described (Steffen et al., 2013), rVSIV-VSIV G control and rVSIV-BASV infectivity decreased with increasing modulator concentrations in the absence of modulator-induced cytotoxicity. As expected, similar results were obtained with all other rVSIVs (Figure 4A).

Although inhibitory trends were similar across all rVSIVs, appreciable differences were observed between individual rVSIVs. For instance, $\mathrm{NH}_{4} \mathrm{Cl}$ almost abrogated VSIV and BASV G-mediated particle entry at a concentration of $<10 \mathrm{mM}$, whereas BAV G-mediated particle entry efficiency was not even halfed. A similar observation was made in the presence of chloroquine; G-mediated particle entry efficiency of almost all rVSIVs reached $0-15 \%$ at $10 \mu \mathrm{M}$, whereas BAV G-mediated particle entry was barely affected at this low concentration.

Rhabdovirions are thought to generally enter cells by clathrin-mediated endocytosis (CME) (Sun et al., 2005; Liu et al., 2011; Cheng et al., 2012; Piccinotti et al., 2013; Weir et al., 2014; Shao et al., 2016). To determine whether this idea can be extended to tibroviruses, we pretreated Vero cells with two CME inhibitors (dynamin inhibitors dynasore and dyngo-4a) and infected the cells as described above. As expected, infectivity of all rVSIVs was inhibited by all three compounds in a dose-dependent manner in the absence of compound-induced cytotoxicity (Figure 4B). Again, differences were observed across the various rVSIVs. Whereas dynosore drastically reduced rVSIV-BASV and rVSIV-EKV-1 particle entry at high $(\geq 100 \mu \mathrm{M})$ concentrations, most other rVSIVs were only moderately affected, and rVSIV-BAV was barely affected. Dyngo-4a, on the other hand, abolished entry of all rVSIVs, but this abolishment was reached at lower concentrations in the case of rVSIV-BASV and rVSIV-EKV-1 $(\approx 15 \mu \mathrm{M})$ compared to most rVSIVs $(\approx 30 \mu \mathrm{M})$.
Together, these results suggest that tibrovirus G-mediated cell entry occurs analogous to that of other rhabdoviruses by low-pHinduced CME, albeit with varying kinetics likely due to structural differences among tibrovirus Gs and resulting differences in $G$ affinities for their binding partners (e.g., receptors).

\section{Authentic Tibrovirion Cell Entry and Infections}

Finally, we evaluated whether tibrovirus cell tropism data obtained with rVSIVs reflect authentic tibrovirus infections. For this experiment, we obtained samples containing the five tibroviruses that were previously isolated in culture (BAV, BHV, CPV, SWBV, and TIBV) (Cybinski et al., 1980; Standfast et al., 1984; Cybinski and Gard, 1986; Gibbs et al., 1989). We succeeded in cultivating all of these viruses except BHV and therefore continued all experiments with the remaining four viruses. Cultured isolates of BASV, EKV-1, and EKV-2 are not available and, therefore, could not be included in the experiment.

The large size of the experiment and the absence of commercially available or generally established tibrovirus detection methods were challenging. Because the first indication of ongoing rhabdovirus replication is the production of rhabdovirus N (Abraham and Banerjee, 1976; Ball and White, 1976; Iverson and Rose, 1981), we aimed to detect tibrovirus cell infection using anti-tibrovirus $\mathrm{N}$ antibodies via western blotting using newly created anti-CPV $\mathrm{N}$ and anti-TIBV $\mathrm{N}$ antibodies. First, these antibodies were tested for cross-reactivity against all four tibroviruses in exposed Asian tiger mosquito and Vero cells. As expected, anti-TIBV $\mathrm{N}$ antibody detected TIBV in these TIBV-infected cells. Anti-CPV N antibody detected $\mathrm{CPV}$ in CPV-exposed Asian tiger mosquito cells but not in Vero cells. Encouragingly, anti-TIBV N antibody also detected BAV (but not CPV and only weakly SWBV) and anti-CPV N antibody also detected SWBV (but not TIBV and only very weakly BAV) (Figure 5A).

We next exposed all human, bat, nonhuman primate, hispid cotton rat, boa constrictor, and Asian tiger mosquito cell lines used in previous experiments (Figures 1-3) to the four authentic tibroviruses and used the respective antibodies to detect $\mathrm{N}$ via western blotting once CPE appeared or otherwise at day 10 post-inoculation (Tables 2, 3). In combination with the results depicted in Figures 2, 3, the results of this experiment suggest that authentic tibrovirus replication does not occur in most cell types after particle entry. For instance, BAV $\mathrm{N}$ could be detected in only six cell lines (four human lung cancer cell lines, one human prostate cancer cell line, and Asian tiger mosquito cells) (Figures 5B,D and Table 2), whereas rVSIV-BAV infected 50 human cell lines (Figure 2) and all other cell lines with the exception of one bat cell line (MyDauLu/47.1) (Figure 3 and Table 3). Likewise, CPV infected only four human cell lines and Asian tiger mosquito cells, and SWBV did not infect any cell line but Asian tiger mosquito cells (Figures 5B,D and Tables 2, 3). The exception to these observations was TIBV, the tibrovirus with the broadest tropism. TIBV $\mathrm{N}$ could be detected in the majority of tested cell lines (Figures 5B-D and Tables 2, 3), which was 

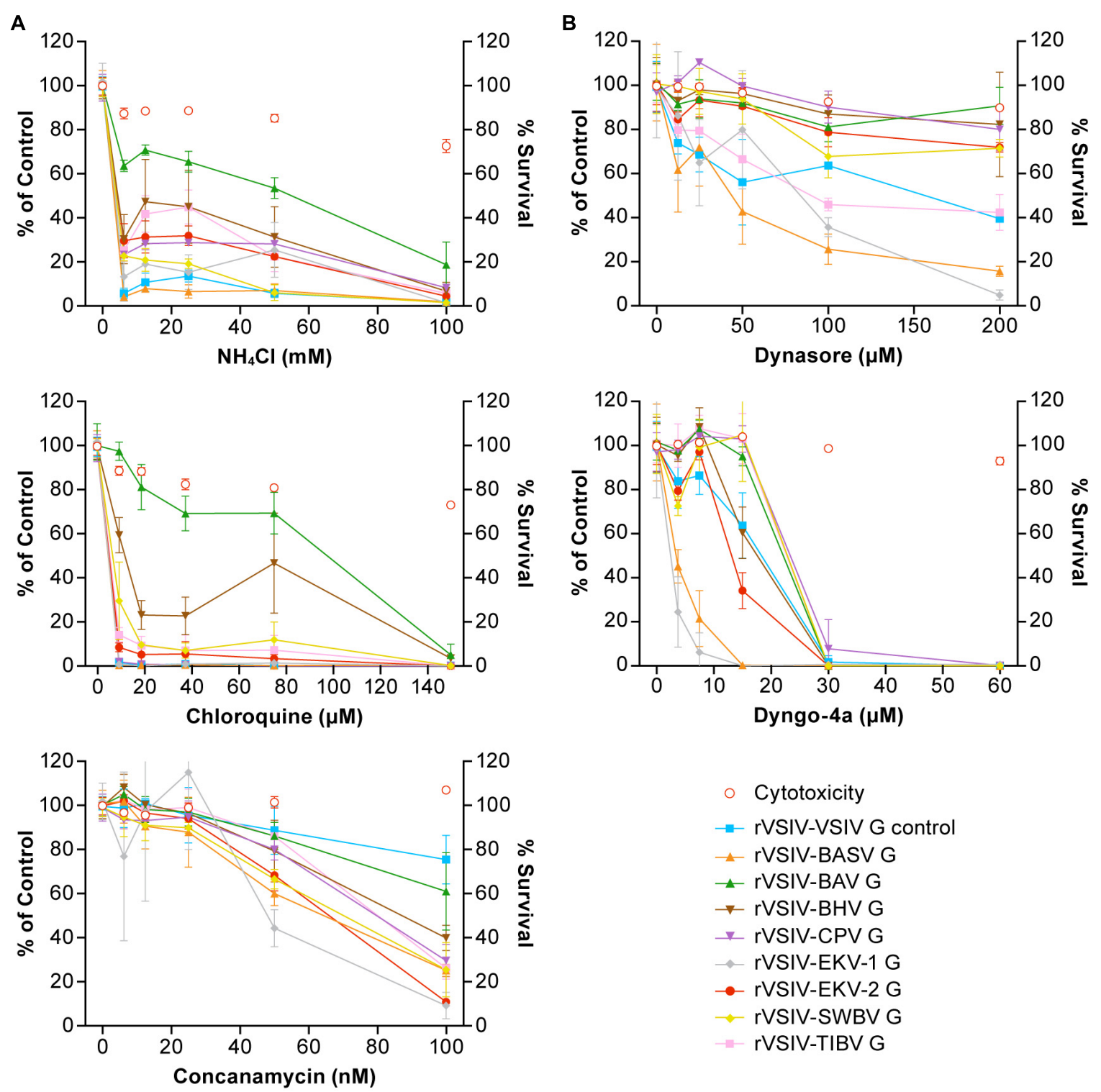

- Cytotoxicity

$\neg$ rVSIV-VSIV G control

$\rightarrow$ rVSIV-BASV G

^ rVSIV-BAV G

$\rightarrow$ rVSIV-BHV G

$\rightarrow$ rVSIV-CPV G

$\rightarrow$ rVSIV-EKV-1 G

$\rightarrow$ rVSIV-EKV-2 G

$\leadsto$ rVSIV-SWBV G

- rVSIV-TIBV G

FIGURE 4 | Tibrovirus particle host cell entry is dependent on low pH and dynamin but is independent of cholesterol. Tibrovirus G-mediated cell entry occurs via a low-pH-dependent, CME-like pathway. (A) Effects of pretreatment of grivet (Vero) cells with increasing concentrations of endosomal pH modulators on cell entry of rVSIV-VSIV G control and rVSIVs expressing diverse tibrovirus glycoproteins (G). (B) Effect of pretreatment of Vero cells with increasing concentrations of CME inhibitors on cell entry of the same viruses as in $\mathbf{A}$. Cells were pretreated with the indicated concentrations of inhibitors for 30 min and then exposed to rVSIVs $(\mathrm{MOI}=0.6)$ in the presence of inhibitors for $1 \mathrm{~h}$ at $37^{\circ} \mathrm{C}$, followed by removal of virus inocula. Total expression levels of eGFP were measured using a Tecan microplate reader at $16 \mathrm{~h}$ post-exposure. BHV, Beatrice Hill virus; BASV, Bas-Congo virus; BAV, Bivens Arm virus; CME, clathrin-mediated endocytosis; CPV, Coastal Plains virus; eGFP, enhanced green fluorescent protein; EKV-1, Ekpoma virus 1; EKV-2, Ekpoma virus 2; MOI, multiplicity of infection; SWBV, Sweetwater Branch virus; TIBV, Tibrogargan virus; rVSIV, recombinant vesicular stomatitis Indiana virus.

largely in agreement with rVSIV-TIBV data (Figures 2, 3). The $\mathrm{N}$ detection results were also largely in agreement with the observation of CPE. For instance, TIBV caused CPE in almost all human cell lines but $\mathrm{N}$ could be detected in two cell lines (human breast cancer Hs-578T and MDA-MB-468) in the absence of CPE (Table 2). In nonhuman cell lines, $\mathrm{N}$ was undetectable in cell lines that did not develop CPE with the exception of four non-human primate cell lines, which expressed $\mathrm{N}$ despite the absence of CPE (Table 3). In contrast, $\mathrm{CPE}$ and $\mathrm{N}$ detection was largely absent in all cell lines infected with BAV, CPV, or SWBV with some individual exceptions. Generally, $\mathrm{N}$ could not be detected in cell lines that did not develop CPE, and $\mathrm{N}$ could be detected in cells that did develop CPE. However, in some cases CPE developed despite the absence of $\mathrm{N}$ detection and vice versa (Tables 2, 3). 


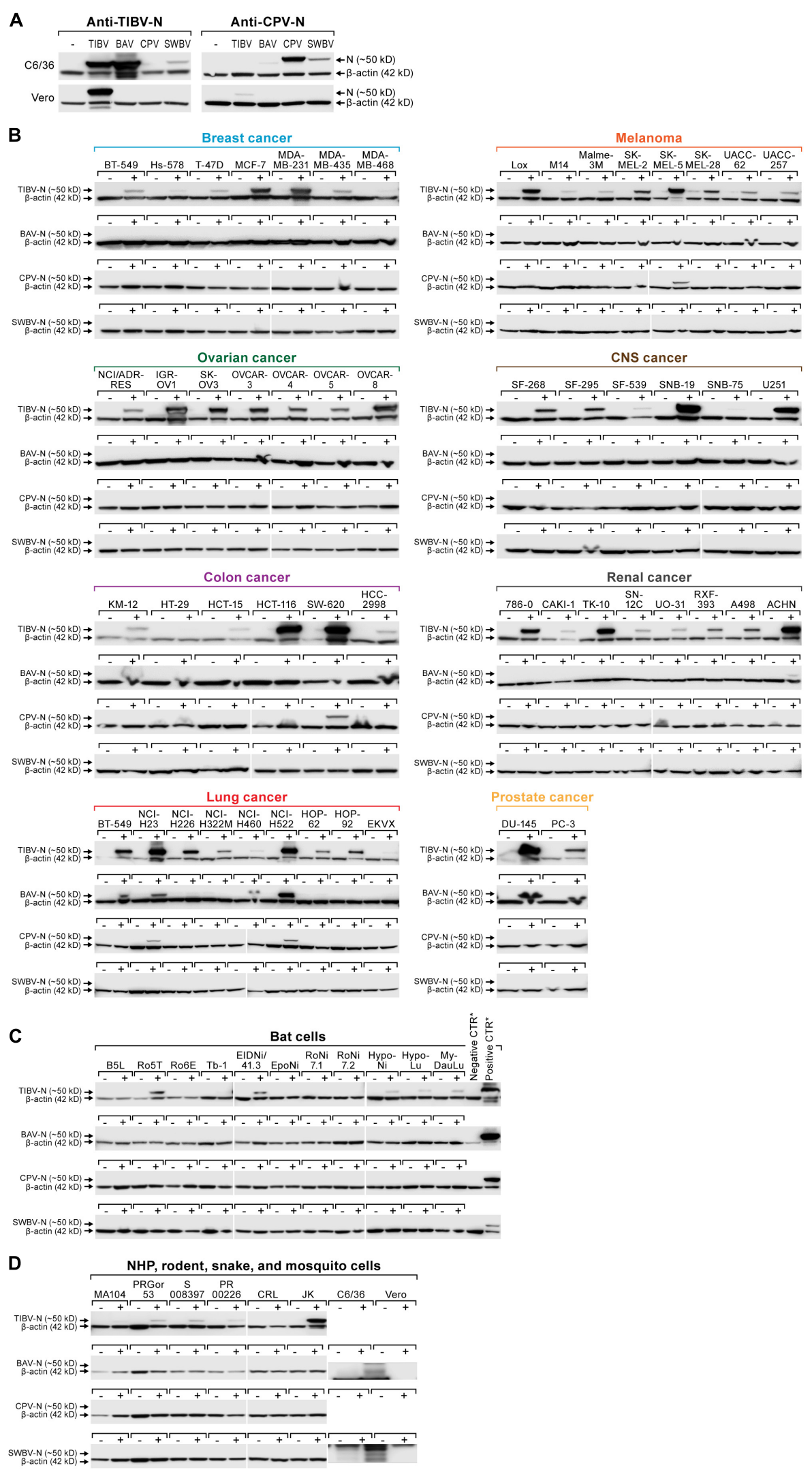

FIGURE 5 | Continued 
FIGURE 5 | Authentic tibrovirion cell entry and infections. (A) Asian tiger mosquito (C6/36) and grivet (Vero) cells were exposed to medium-only control (-), BAV, CPV, SWBV, or TIBV particle preparations. Virion entry was detected via western blotting using an anti-TIBV N antibody (here shown to be strongly cross-reactive with BAV in C6/36 cells and weakly cross-reactive with SWBV) and an anti-CPV N antibody (here shown to be cross-reactive with SWBV in C6/36 cells and very weakly cross-reactive with BAV). (B) NCl-60 cells, (C) bat cells, and (D) nonhuman primate (NHP), hispid cotton rat, boa constrictor, and Asian tiger mosquito cells (see also Figure 3) were exposed to medium-only control (-) or BAV, CPV, SWBV, or TIBV (+). Cell lysates were harvested after the appearance of CPE or otherwise at day 10 post-exposure (Table 2). Tibovirion entry was detected via western blotting using the appropriate anti-TIBV, BAV, SWBV, and anti-CPV N antibodies. Protein loading was controlled by detecting $\beta$-actin. BAV, Bivens Arm virus; CPV, Coastal Plains virus; N, nucleoprotein; NCI, National Cancer Institute; SWBV, Sweetwater Branch virus; TIBV, Tibrogargan virus.

\section{DISCUSSION}

Tibroviruses are highly undercharacterized rhabdoviruses with unknown pathogenic potential. All isolated tibroviruses (BAV, BHV, CPV, SWBV, and TIBV) have only been found in biting midge vectors or in various, apparently healthy non-human mammals (Cybinski et al., 1980; Standfast et al., 1984; Cybinski and Gard, 1986; Gibbs et al., 1989). The discovery of BASV, EKV-1, and EKV-2 genomes in human sera (Grard et al., 2012; Stremlau et al., 2015) suggests that at least some tibroviruses could infect humans. Because BASV was discovered in the serum of a severely ill individual, tibroviruses should be considered potential human pathogens for surveillance purposes until this hypothesis is ruled out.

In this initial study, we aimed to comprehensively characterize the host and cell type tropism of tibroviruses to determine whether tibroviruses in general can enter human and other animal cells. Previous studies on this topic have been extremely limited. BAV and SWBV were isolated in Asian tiger mosquito (C6/36) cells, and all attempts to grow them in baby golden hamster (Mesocricetus auratus) kidney (BHK-21) and adult grivet (C. aethiops) kidney (Vero) cells failed (Gibbs et al., 1989). BHV was isolated only in porcine stable-equine kidney (PS-EK) cells (Standfast et al., 1984) and in C6/36 cells after a single Vero cell passage (Huang et al., 2016). CPV was isolated in BHK-21, C6/36 cells, and Vero cells (Cybinski and Gard, 1986). TIBV was originally isolated in suckling laboratory mice and could be grown in BHK-21 and Vero cells (Cybinski et al., 1980). To our knowledge, no further data on cell or animal tropism of replicating tibroviruses have been reported.

In 2013, Steffen et al. (2013) reported the evaluation of BASV cell entry using an eGFP-expressing VSIV pseudotyped with BASV G. Using this system, the authors demonstrated that BASV G successfully mediates VSIV particle entry into human B lymphocytes (B-THP), cervix (HeLa), colon (SW480), and colon carcinoma (CaCo-2) cells, erythroblasts (HEL), fibrosarcoma (HT1080), liver (Huh-7.5), and lung (A549) cells, and monocytes (THP-1), muscle (RD) cells, and T lymphocytes (Jurkat, H9). The same pseudotype system was used to demonstrate that BASV G-mediated VSIV entry into adult grivet kidney (Vero), Asian tiger mosquito larva (C6/36, C7/10), aurochs (Bos taurus) kidney (MDBK), BHK-21, Brazilian free-tailed bat (T. brasiliensis) lung (Tb1 Lu), brown rat (Rattus norvegicus) kidney (NRK) and brain (C6) cells, domestic pig (Sus scrofa) kidney (SK-RST) cells, and house mouse (Mus musculus) fibroblasts (3T3, MC57) (Steffen et al., 2013). These experiments suggested that BASV particles can enter a broad range of cells from diverse animal species, including
Homo sapiens. This result stands in contrast to the knowledge available at the time on tropism of other tibroviruses.

Our systematic approach sheds further light on tibrovirion cell entry abilities. Together, our results indicate that all tibrovirus Gs, not only BASV G, can mediate tibrovirus particle entry into a wide variety of cells derived from animals of diverse species, including $H$. sapiens (Figures 2, 3, 5). The most surprising result was that EKV-1 and EKV-2, which had been discovered in human sera (Stremlau et al., 2015), appeared so much more efficient in entering human cells than BASV, the only other tibrovirus found in humans thus far (Grard et al., 2012) (Figure 2).

However, our results need to be regarded with caution. First, it is important to emphasize that our data only indicate which cell lines allow entry of particles of diverse tibroviruses, but we cannot state which of these tibrovirion-susceptible cells are also permissive to tibrovirus replication, particle formation, and particle egress. For instance, BASV, EKV-1, and/or EKV-2 could possibly enter numerous human cell types in vivo but then be restricted via antiviral pathways of the penetrated cells in replication and virion progeny formation. Indeed, $\mathrm{N}$-detecting western blots using cells infected with four authentic tibroviruses (Figure 5) suggest that most cell lines are resistant to productive tibrovirus infection (absence of CPE and/or N expression) with the notable exception of TIBV. Vice versa, in Asian tiger mosquito (C6/36) cells, which lack a functional RNAi antiviral response (Brackney et al., 2010), all four authentic tibroviruses replicated efficiently. We measured $\mathrm{N}$ expression only at one timepoint due to the scale of the experiment, and we were unable to carefully quantify the titer and infectious-to-noninfectious particle ratios for the cell infection experiments. Hence, lack of $\mathrm{N}$ detection could be due to delayed or slow replication, whereas $\mathrm{N}$ detection could be partially due to detection of $\mathrm{N}$ stemming from incoming virions rather than from newly made transcripts.

Second, the passaging histories of all isolated tibroviruses used in our study are complex, involving cells and animals of different species (Table 1). Unpassaged or low-passaged tibroviruses or tibrovirus sequences (or original samples) are not available anymore. Because the tibrovirus $G$ sequences used for the creation of rVSIVs for this study were ultimately derived from these passaged viruses (Gubala et al., 2011; Lauck et al., 2015; Walker et al., 2015), we can only claim that those viruses enter animal cells efficiently, but we cannot extrapolate these results to wild-type tibroviruses.

Interestingly, authentic TIBV entered (and likely infected) the majority of tested cell lines (Figure 5) largely in agreement with rVSIV-TIBV data (Figures 2, 3). This result is somewhat puzzling as the closest relative of TIBV, BAV, which is classified in the same 
species as TIBV (Walker et al., 2015), did not cause CPE in most cell lines and BAV $\mathrm{N}$ could not be detected in them via western blotting, either. One explanation for this discrepancy is that the TIBV isolate we obtained evolved to be able to use mammalian and reptilian cells during repeated in vitro and in vivo passaging over the last decades, whereas BAV evolution took a different path because of a different passaging history (Table 1). In that regard, the experiment with BAV also produced individual puzzling results: for instance, three human cancer cell lines (melanoma M14, human colon cancer HCC-2998, and renal cancer A498) developed CPE after BAV exposure but BAV $\mathrm{N}$ could not be detected. Vice versa, four human cell lines (renal cancer ACHN, lung cancer A549, NCI-H23, and NCI-H460) did not develop CPE but BAV N could be detected. The latter result could indicate nondetrimental viral replication (or detection of incoming virion $\mathrm{N}$ ), whereas the former result remains to be explained.

Together, the data obtained during our study indicate that tibrovirus tropism evaluations using tibrovirus surrogate systems (such as pseudotyped VSIVs or rVSIVs) should not be interpreted as indicative of the actual ability of a tibrovirus to infect, for instance, humans. However, these studies will be useful to further evaluate the general entry mechanism of tibroviruses, including, for instance, the identification of (the) tibrovirus cell surface receptor(s), which appear to be rather ubiquitously expressed. To evaluate the pathogenic potential of alleged human tibroviruses such as BASV, EKV-1, and EKV-2, replicating isolates will have to be obtained either by means of isolation from a natural host reservoir or vector or by means of reverse genetics.

\section{AUTHOR CONTRIBUTIONS}

YC, SY, EP, ML, MW, CF, and SR performed the experiments. $\mathrm{RJ}$, SW, and $\mathrm{KC}$ developed and grew rVSIVs expressing tibrovirus G glycoproteins. RT grew tibrovirus stocks. JW, DO, GP, CC, and JK planned experiments and analyzed the data. JK wrote the manuscript. All authors reviewed and approved the manuscript.

\section{FUNDING}

This work was funded in part through Battelle Memorial Institute's prime contract with the US National Institute of

\section{REFERENCES}

Abraham, G., and Banerjee, A. K. (1976). Sequential transcription of the genes of vesicular stomatitis virus. Proc. Natl. Acad. Sci. U.S.A. 73, 1504-1508.

Altstiel, L. D., and Landsberger, F. R. (1981). Lipid-protein interactions between the surface glycoprotein of vesicular stomatitis virus and the lipid bilayer. Virology $115,1-9$.

Babayan, S. A., Orton, R. J., and Streicker, D. G. (2018). Predicting reservoir hosts and arthropod vectors from evolutionary signatures in RNA virus genomes. Science 362, 577-580. doi: 10.1126/science.aap9072

Ball, L. A., and White, C. N. (1976). Order of transcription of genes of vesicular stomatitis virus. Proc. Natl. Acad. Sci. U.S.A. 73, 442-446.
Allergy and Infectious Diseases (NIAID) under Contract No. HHSN272200700016 (YC, SY, EP, JW, CF, and JK) and in part through National Institutes of Health (NIH) grant R01 AI132633 (RJ and $\mathrm{KC}$ ).

\section{ACKNOWLEDGMENTS}

We would like to thank Charles H. Calisher (Colorado State University, Fort Collins, CO, USA), Ania Gubala (CSIRO, Australia), and Toby St. George (Australia) for sharing knowledge and historic reports on tibroviruses, and Laura Bollinger (IRF-Frederick, Frederick, MD, USA) for critically editing the manuscript.

\section{SUPPLEMENTARY MATERIAL}

The Supplementary Material for this article can be found online at: https://www.frontiersin.org/articles/10.3389/fmicb. 2019.00856/full\#supplementary-material

FIGURE S1 | Tibrovirus glycoproteins mediate virion entry into a broad range of human cell types. (A) Same experiment as in Figure 1B and (B) as in Figure 2 using rVSIVs expressing diverse tibrovirus glycoproteins $(\mathrm{G})(\mathrm{MOI}=0.3)$. The percentage of eGFP-expressing NCl-60 human cell panel cell lines was measured by high-content imaging at $24 \mathrm{~h}$ post-exposure. All experiments were performed in triplicate; error bars show standard deviations. BHV, Beatrice Hill virus; BASV, Bas-Congo virus; BAV, Bivens Arm virus; CNS, central nervous system; CPV; Coastal Plains virus; EKV-1, Ekpoma virus 1; eGFP, enhanced green fluorescent protein; EKV-2, Ekpoma virus 2; MOI, multiplicity of infection; SWBV, Sweetwater Branch virus; TIBV, Tibrogargan virus; rVSIV, recombinant vesicular stomatitis Indiana virus. $\mathrm{NCl}-60$ cell lines are listed by their abbreviations and grouped by organ/cancer type.

FIGURE S2 | Tibrovirus glycoproteins mediate virion entry into a broad range of animal cell types. Same experiment as in Figure $\mathbf{3}$ using different cell types exposed to rVSIV-VSIV G control and rVSIVs expressing diverse tibrovirus glycoproteins $(\mathrm{G})(\mathrm{MOI}=0.3)$. Bat (PESU-B5L, Ro5T, Ro6E, EidNi/41.3, EpoNi/22.1, RoNi/7.1, RoNi/7.2, HypNi/1.1, HypLu/45.1, Tb1 Lu, MyDauLu/47.1), nonhuman primate (Vero, MA104, RPGor53, S008397, RP00226), hispid cotton rat $\mathrm{CRL}$, and boa constrictor JK cell lines. The percentage of eGFP-expressing cell lines was measured by high-content imaging at $24 \mathrm{~h}$ post-exposure. All experiments were performed in triplicate; error bars show standard deviations. $\mathrm{BHV}$, Beatrice Hill virus; BASV, Bas-Congo virus; BAV, Bivens Arm virus; CPV, Coastal Plains virus; eGFP, enhanced green fluorescent protein; EKV-1, Ekpoma virus 1; EKV-2, Ekpoma virus 2; SWBV, Sweetwater Branch virus; TIBV,

Tibrogargan virus; rVSIV, recombinant vesicular stomatitis

Indiana virus. 
Bourhy, H., Cowley, J. A., Larrous, F., Holmes, E. C., and Walker, P. J. (2005). Phylogenetic relationships among rhabdoviruses inferred using the $\mathrm{L}$ polymerase gene. J. Gen. Virol. 86(Pt 10), 2849-2858. doi: 10.1099/vir.0.81128-0

Brackney, D. E., Scott, J. C., Sagawa, F., Woodward, J. E., Miller, N. A., Schilkey, F. D., et al. (2010). C6/36 Aedes albopictus cells have a dysfunctional antiviral RNA interference response. PLoS Negl. Trop. Dis. 4:e856. doi: 10.1371/journal. pntd.0000856

Buchko, G. W., Clifton, M. C., Wallace, E. G., Atkins, K. A., and Myler, P. J. (2017). Backbone chemical shift assignments and secondary structure analysis of the U1 protein from the Bas-Congo virus. Biomol. NMR Assign. 11, 51-56. doi: 10.1007/s12104-016-9719-2

Calisher, C. H., Borde, G. E. N., Tuekam, T., and Gibbs, E. P. J. (1993). “Antibody to Bivens Arm virus in Trinidadian buffalo: a temporal and evolutionary link between Australia, Asia and the Caribbean?" in Proceedings of the Bovine Ephemeral Fever and Related Rhabdoviruses. 1st International Symposium, Bovine Ephemeral Fever and Related Rhabdoviruses (Canberra, ACT: ACIAR), 80-83.

Cheng, C. Y., Shih, W. L., Huang, W. R., Chi, P. I., Wu, M. H., and Liu, H. J. (2012). Bovine ephemeral fever virus uses a clathrin-mediated and dynamin 2-dependent endocytosis pathway that requires Rab5 and Rab7 as well as microtubules. J. Virol. 86, 13653-13661. doi: 10.1128/jvi.01073-12

Chiu, C., Fair, J., and Leroy, E. M. (2013). Bas-Congo virus: another deadly virus? Future Microbiol. 8, 139-141. doi: 10.2217/fmb.12.145

Cybinski, D. H., and Gard, G. P. (1986). Isolation of a new rhabdovirus in Australia related to Tibrogargan virus. Aust. J. Biol. Sci. 39, 225-232.

Cybinski, D. H., St. George, T. D., Standfast, H. A., and McGregor, A. (1980). Isolation of Tibrogargan virus, a new Australian rhabdovirus, from Culicoides brevitaris. Vet. Microbiol. 5, 301-308.

Finkelshtein, D., Werman, A., Novick, D., Barak, S., and Rubinstein, M. (2013). LDL receptor and its family members serve as the cellular receptors for vesicular stomatitis virus. Proc. Natl. Acad. Sci. U.S.A. 110, 7306-7311. doi: 10.1073/pnas. 1214441110

Florkiewicz, R. Z., and Rose, J. K. (1984). A cell line expressing vesicular stomatitis virus glycoprotein fuses at low $\mathrm{pH}$. Science 225, 721-723.

Garbutt, M., Liebscher, R., Wahl-Jensen, V., Jones, S., Möller, P., Wagner, R., et al. (2004). Properties of replication-competent vesicular stomatitis virus vectors expressing glycoproteins of filoviruses and arenaviruses. J. Virol. 78, 5458-5465.

Gard, G. P., Shorthose, J. E., Weir, R. P., Walsh, S. J., and Melville, L. F. (1988). Arboviruses recovered from sentinel livestock in northern Australia. Vet. Microbiol. 18, 109-118.

Gaudin, Y., Ruigrok, R. W. H., Knossow, M., and Flamand, A. (1993). Low-pH conformational changes of rabies virus glycoprotein and their role in membrane fusion. J. Virol. 67, 1365-1372.

Gibbs, E. P., Calisher, C. H., Tesh, R. B., Lazuick, J. S., Bowen, R., and Greiner, E. C. (1989). Bivens Arm virus: a new rhabdovirus isolated from Culicoides insignis in Florida and related to Tibrogargan virus of Australia. Vet. Microbiol. 19, 141-150.

Grard, G., Fair, J. N., Lee, D., Slikas, E., Steffen, I., Muyembe, J.-J., et al. (2012). A novel rhabdovirus associated with acute hemorrhagic fever in Central Africa. PLoS Pathog. 8:e1002924. doi: 10.1371/journal.ppat.1002924

Gubala, A., Davis, S., Weir, R., Melville, L., Cowled, C., and Boyle, D. (2011). Tibrogargan and coastal plains rhabdoviruses: genomic characterization, evolution of novel genes and seroprevalence in Australian livestock. J. Gen. Virol. 92(Pt 9), 2160-2170. doi: 10.1099/vir.0.026120-0

Hastie, E., Cataldi, M., Marriott, I., and Grdzelishvili, V. Z. (2013). Understanding and altering cell tropism of vesicular stomatitis virus. Virus Res. 176, 16-32. doi: 10.1016/j.virusres.2013.06.003

Hoffmann, M., Müller, M. A., Drexler, J. F., Glende, J., Erdt, M., Gützkow, T., et al. (2013). Differential sensitivity of bat cells to infection by enveloped RNA viruses: coronaviruses, paramyxoviruses, filoviruses, and influenza viruses. PLoS One 8:e72942. doi: 10.1371/journal.pone.0072942

Huang, B., Allcock, R., and Warrilow, D. (2016). Newly characterized arboviruses of northern Australia. Virol. Rep. 6, 11-17. doi: 10.1016/j.virep.2016. 01.001

Huynh, J., Li, S., Yount, B., Smith, A., Sturges, L., Olsen, J. C., et al. (2012). Evidence supporting a zoonotic origin of human coronavirus strain NL63. J. Virol. 86, 12816-12825. doi: 10.1128/jvi.00906-12
Iverson, L. E., and Rose, J. K. (1981). Localized attenuation and discontinuous synthesis during vesicular stomatitis virus transcription. Cell 23, 477-484.

Jangra, R. K., Herbert, A. S., Li, R., Jae, L. T., Kleinfelter, L. M., Slough, M. M., et al. (2018). Protocadherin-1 is essential for cell entry by New World hantaviruses. Nature 563, 559-563. doi: 10.1038/s41586-018-0702-1

Jordan, I., Horn, D., Oehmke, S., Leendertz, F. H., and Sandig, V. (2009). Cell lines from the Egyptian fruit bat are permissive for modified vaccinia Ankara. Virus Res. 145, 54-62. doi: 10.1016/j.virusres.2009.06.007

Kleinfelter, L. M., Jangra, R. K., Jae, L. T., Herbert, A. S., Mittler, E., Stiles, K. M., et al. (2015). Haploid genetic screen reveals a profound and direct dependence on cholesterol for hantavirus membrane fusion. mBio 6:e00801. doi: 10.1128/ mBio.00801-15

Kühl, A., Hoffmann, M., Müller, M. A., Munster, V. J., Gnirß, K., Kiene, M., et al. (2011). Comparative analysis of Ebola virus glycoprotein interactions with human and bat cells. J. Infect. Dis. 204(Suppl. 3), S840-S849. doi: 10.1093/infdis/ jir306

Lafon, M. (2005). Rabies virus receptors. J. Neurovirol. 11, 82-87. doi: 10.1080/ 13550280590900427

Lauck, M., Yú, S., Caì, Y., Hensley, L. E., Chiu, C. Y., O’Connor, D. H., et al. (2015). Genome sequence of bivens arm virus, a tibrovirus belonging to the species Tibrogargan virus (Mononegavirales: Rhabdoviridae). Genome Announc. 3:e89-15. doi: 10.1128/genomeA.00089-15

Liu, H., Liu, Y., Liu, S., Pang, D.-W., and Xiao, G. (2011). Clathrin-mediated endocytosis in living host cells visualized through quantum dot labeling of infectious hematopoietic necrosis virus. J. Virol. 85, 6252-6262. doi: 10.1128/ jvi.00109-11

Maes, P., Amarasinghe, G. K., Ayllón, M. A., Basler, C. F., Bavari, S., Blasdell, K. R., et al. (2019). Taxonomy of the order Mononegavirales: second update 2018. Arch. Virol. 164, 1233-1244. doi: 10.1007/s00705-018-04126-4

Moreira, ÉA., Locher, S., Kolesnikova, L., Bolte, H., Aydillo, T., García-Sastre, A., et al. (2016). Synthetically derived bat influenza A-like viruses reveal a cell typebut not species-specific tropism. Proc. Natl. Acad. Sci. U.S.A. 113, 12797-12802. doi: $10.1073 /$ pnas. 1608821113

Piccinotti, S., Kirchhausen, T., and Whelan, S. P. J. (2013). Uptake of rabies virus into epithelial cells by clathrin-mediated endocytosis depends upon actin. J. Virol. 87, 11637-11647. doi: 10.1128/jvi.01648-13

Raaben, M., Jae, L. T., Herbert, A. S., Kuehne, A. I., Stubbs, S. H., Chou, Y.-Y., et al. (2017). NRP2 and CD63 are host factors for Lujo virus cell entry. Cell Host Microbe 22, 688-696.e5. doi: 10.1016/j.chom.2017.10.002

Regan, A. D., and Whittaker, G. R. (2013). Entry of rhabdoviruses into animal cells. Adv. Exp. Med. Biol. 790, 167-177. doi: 10.1007/978-1-4614-7651-1_9

Robinson, L. R., and Whelan, S. P. J. (2016). Infectious entry pathway mediated by the human endogenous retrovirus K envelope protein. J. Virol. 90, 3640-3649. doi: 10.1128/jvi.03136-15

Shao, L., Zhao, J., and Zhang, H. (2016). Spring viraemia of carp virus enters grass carp ovary cells via clathrin-mediated endocytosis and macropinocytosis. J. Gen. Virol. 97, 2824-2836. doi: 10.1099/jgv.0.000595

St George, T. D. (1985). Studies on the pathogenesis of bovine ephemeral fever in sentinel cattle. I. Virology and serology. Vet. Microbiol. 10, 493-504.

Standfast, H. A., Dyce, A. L., St George, T. D., Muller, M. J., Doherty, R. L., Carley, J. G., et al. (1984). Isolation of arboviruses from insects collected at Beatrice Hill, Northern Territory of Australia, 1974-1976. Aust. J. Biol. Sci. 37, 351-366.

Steffen, I., Liss, N. M., Schneider, B. S., Fair, J. N., Chiu, C. Y., and Simmons, G. (2013). Characterization of the Bas-Congo virus glycoprotein and its function in pseudotyped viruses. J. Virol. 87, 9558-9568. doi: 10.1128/JVI. 01183-13

Stenglein, M. D., Sanders, C., Kistler, A. L., Ruby, J. G., Franco, J. Y., Reavill, D. R., et al. (2012). Identification, characterization, and in vitro culture of highly divergent arenaviruses from boa constrictors and annulated tree boas: candidate etiological agents for snake inclusion body disease. mBio 3:e180-12. doi: $10.1128 / \mathrm{mBio} .00180-12$

Stremlau, M. H., Andersen, K. G., Folarin, O. A., Grove, J. N., Odia, I., Ehiane, P. E., et al. (2015). Discovery of novel rhabdoviruses in the blood of healthy individuals from West Africa. PLoS Negl. Trop. Dis. 9:e0003631. doi: 10.1371/ journal.pntd.0003631

Sun, X., Yau, V. K., Briggs, B. J., and Whittaker, G. R. (2005). Role of clathrinmediated endocytosis during vesicular stomatitis virus entry into host cells. Virology 338, 53-60. doi: 10.1016/j.virol.2005.05.006 
Tani, H., Morikawa, S., and Matsuura, Y. (2011). Development and applications of VSV vectors based on cell tropism. Front. Microbiol. 2:272. doi: 10.3389/fmicb. 2011.00272

The University of Texas Medical Branch (UTMB) (2018). World Reference Center for Emerging Viruses and Arboviruses. Available at: https://www.utmb.edu/gnl/ research/wrceva (accessed April 15, 2019).

Tuekam, T., Greiner, E. C., and Gibbs, E. P. (1991). Seroepidemiology of Bivens Arm virus infections of cattle in Florida, St. Croix and Puerto Rico. Vet. Microbiol. 28, 121-127.

Walker, P. J., Blasdell, K. R., Calisher, C. H., Dietzgen, R. G., Kondo, H., Kurath, G., et al. (2018). ICTV virus taxonomy profile: Rhabdoviridae. J. Gen. Virol. 99, 447-448. doi: 10.1099/jgv.0.001020

Walker, P. J., Firth, C., Widen, S. G., Blasdell, K. R., Guzman, H., Wood, T. G., et al. (2015). Evolution of genome size and complexity in the Rhabdoviridae. PLoS Pathog. 11:e1004664. doi: 10.1371/journal.ppat.1004664

Weinstein, J. N. (2006). Spotlight on molecular profiling: "Integromic" analysis of the NCI-60 cancer cell lines. Mol. Cancer Ther. 5, 2601-2605. doi: 10.1158/ 1535-7163.mct-06-0640

Weir, D. L., Laing, E. D., Smith, I. L., Wang, L.-F., and Broder, C. C. (2014). Host cell virus entry mediated by Australian bat lyssavirus $\mathrm{G}$ envelope glycoprotein occurs through a clathrin-mediated endocytic pathway that requires actin and Rab5. Virol. J. 11:40. doi: 10.1186/1743-422x-11-40

Wiley, M. R., Prieto, K., Blasdell, K. R., Caì, Y., Campos Lawson, C., Walker, P. J., et al. (2017). Beatrice Hill virus represents a novel species in the genus Tibrovirus (Mononegavirales: Rhabdoviridae). Genome Announc. 5:e1485-16. doi: 10.1128/genomeA.01485-16
Wong, A. C., Sandesara, R. G., Mulherkar, N., Whelan, S. P., and Chandran, K. (2010). A forward genetic strategy reveals destabilizing mutations in the ebolavirus glycoprotein that alter its protease dependence during cell entry. J. Virol. 84, 163-175. doi: 10.1128/JVI. 01832-09

Wunner, W. H., Reagan, K. J., and Koprowski, H. (1984). Characterization of saturable binding sites for rabies virus. J. Virol. 50, 691-697.

Disclaimer: The content of this publication does not necessarily reflect the views or policies of the US Department of the Army, the US Department of Defense, or the US Department of Health and Human Services or of the institutions and companies affiliated with the authors.

Conflict of Interest Statement: The authors declare that the research was conducted in the absence of any commercial or financial relationships that could be construed as a potential conflict of interest.

Copyright (c) 2019 Caì, Yú, Jangra, Postnikova, Wada, Tesh, Whelan, Lauck, Wiley, Finch, Radoshitzky, O'Connor, Palacios, Chandran, Chiu and Kuhn. This is an openaccess article distributed under the terms of the Creative Commons Attribution License (CC BY). The use, distribution or reproduction in other forums is permitted, provided the original author(s) and the copyright owner(s) are credited and that the original publication in this journal is cited, in accordance with accepted academic practice. No use, distribution or reproduction is permitted which does not comply with these terms. 